\title{
Power Withstanding Capability and Transient Temperature of Carbon Nanotube-Based Nano Electrical Interconnects
}

Femi Robert ( $\nabla$ r.femi85@gmail.com )

SRM Institute of Science and Technology, Kattankullathur Campus, Chennai https://orcid.org/00000002-6143-6372

\section{Research Article}

Keywords: Carbon Nanotube, electrical interconnects, finite element modelling, electrothermal analysis, nanoelectronic devices

Posted Date: February 12th, 2021

DOI: https://doi.org/10.21203/rs.3.rs-188713/v1

License: (a) (i) This work is licensed under a Creative Commons Attribution 4.0 International License.

Read Full License 


\title{
Power Withstanding Capability and Transient Temperature of Carbon Nanotube-Based Nano Electrical Interconnects
}

\author{
Femi Robert \\ Department of Electrical and Electronics Engineering, SRM Institute of Science and Technology, \\ Kattankullathur Campus, Chennai-603203 \\ r.femi85@gmail.com \\ https://orcid.org/0000-0002-6143-6372
}

\begin{abstract}
This paper exhibits the electrothermal modelling and evaluation of Carbon Nanotube (CNT) based electrical interconnects for electronic devices. The continuum model of the CNT is considered and the temperature across interconnect is predicted for the given power. Finite element modelling software COMSOL Multiphysics is used to carry out the simulations. The results are compared with $\mathrm{Al}$ and $\mathrm{Cu}$ interconnects. An electrothermal analysis is also carried out to obtain the temperature for the given power for Single-Walled CNT, Double-Walled CNT, Triple-Walled CNT, and Multi-Walled CNT. Results show that the CNT interconnects performs better when compared to $\mathrm{Al}$ and $\mathrm{Cu}$ interconnects. The power withstanding capability of $\mathrm{CNT}$ is 68.75 times more than $\mathrm{Al}$ and 32.35 times more than $\mathrm{Cu}$. Based on the transient analysis, the time taken by the CNT interconnects to reach a steady temperature is obtained as $0.007 \mathrm{~ns}$. On the application of power, $\mathrm{Cu}$ and $\mathrm{Al}$ interconnects takes $0.1 \mathrm{~ns}$ to reach the steady-state temperature. The nanostructured CNT based electrical interconnects would play a considerable role in replacing Cu and Al electrical interconnect applications for micro and nanoelectronic devices.
\end{abstract}

Keywords—Carbon Nanotube, electrical interconnects, finite element modelling, electrothermal analysis, nanoelectronic devices

\section{Introduction}

The advances in semiconductor devices miniaturized the electronic circuits. The cost of the transistors reduced by half and the number transistors within a chip increased two times as per Moore's law [1]. In the near future, trillion transistors in a terascale chip would have a minimum feature size of $10 \mathrm{~nm}$ [2]. The transistor speed has been increased considerably. But the performance of electrical interconnects have been reduced because of the high electron scattering probability and lower conduction area [3, 4]. The performance of the electronic circuits become poor because of the scaling down in the size of interconnects and increased power dissipation. This reduces the reliability of interconnects. Copper $(\mathrm{Cu})$ and $\mathrm{Aluminium}(\mathrm{Al})$ are the commonly used interconnect materials. At the temperature of $20{ }^{0} \mathrm{C}, \mathrm{Cu}$ has the resistivity of $1.68 \times 10^{-8} \Omega \mathrm{m}$ and electrical conductivity of $59.6 \mathrm{MS} / \mathrm{m}$. The density of $\mathrm{Cu}$ and $\mathrm{Al}$ are $0.00896 \mathrm{~g} / \mathrm{mm}^{3}$ and $0.00271 \mathrm{~g} / \mathrm{mm}^{3}$ respectively. Hence $\mathrm{Cu}$ interconnect is heavier than $\mathrm{Al}$ interconnect. At $20{ }^{0} \mathrm{C}$, $\mathrm{Al}$ has the resistivity of $2.65 \times 10^{-8} \Omega \mathrm{m}$ and electrical conductivity of 37.7 MS/m. Because of the high resistivity more power loss occurs across $\mathrm{Al}$ interconnects than $\mathrm{Cu}$ interconnects. When $\mathrm{Cu}$ and $\mathrm{Al}$ interconnects operated at higher frequencies, it experiences skin effect [5]. $\mathrm{Cu}$ has an ultimate and yield tensile strength of $210 \mathrm{MPa}$ and $70 \mathrm{MPa}$ respecively. Al has the ultimate and yield tensile strength of $110 \mathrm{MPa}$ and $95 \mathrm{MPa}$. The modulus of elasticity of $\mathrm{Cu}$ and $\mathrm{Al}$ are $117 \mathrm{GPa}$ and $69 \mathrm{GPa}$ respectively. Al interconnects are more likely to break than $\mathrm{Cu}$ interconnects because of the lower tensile strength. The most preferred and commonly used material for interconnect is $\mathrm{Cu}$, because of its lower cost, malleability, ductility, high melting point, longevity, low reactivity rating, higher electrical conductivity and resistant to heat. In addition to this, the manufacturing of $\mathrm{Al}$ and $\mathrm{Cu}$ with less than $100 \mathrm{~nm}$ diameter involves higher challenges $[6,7]$. It is important to design interconnect to support future transistors with $1 \mathrm{~nm}$ technology node [8]. The future requirements of interconnects cannot be satisfied by $\mathrm{Al}$ and $\mathrm{Cu}$, because of the limited current carrying capability. Designing reliable nanoscale interconnects is highly required for future transistors, electronic devices and integrated circuits (ICs) [9].

In the past few decades, carbon nanomaterials are extensively investigated by researchers. Carbon allotropes have attracted more research interest in which CNT and Graphene show excellent electrical, thermal and mechanical properties. These 
materials can be deposited and grown in desired locations. The shape of the commonly used electrical interconnects is cylinder and rectangle. CNTs can be used as cylindrical interconnects and graphene can be used as rectangular nanoribbons [10]. CNT interconnects in nanoscale have advantages such as stability at extreme conditions, ability to withstand harsh chemicals and working at high temperatures. The melting and boiling temperature of the CNT are $3550{ }^{\circ} \mathrm{C}$ and $4027{ }^{\circ} \mathrm{C}$. CNTs have a symmetrical and one-dimensional structure in which the charge carriers can move along the tube without scattering. The resistivity of individual CNTs is in the order of $10^{-8} \Omega \mathrm{m}$ which is because to the absence of scattering. The electrical conductivity of CNTs ranges from $10^{6}$ to $10^{7} \mathrm{~S} / \mathrm{m}$. The density of CNT wire is $0.0014 \mathrm{~g} / \mathrm{mm}^{3}$ to $0.00226 \mathrm{~g} / \mathrm{mm}^{3}$ which is comparatively lesser than $\mathrm{Cu}$ and $\mathrm{Al}$. This makes the $\mathrm{CNT}$ electrical interconnects lighter [11, 12].

CNTs have a tubular shape and tunable electrical properties. They have excellent properties such as low density, less skin effect, ballistic electron transport, high mechanical strength, high thermal conductivity and more stiffness than metals. The carbon sources are abundantly available and CNTs can be manufactured on a large scale with zero net carbon footprint at low-cost. These attributes make CNTs a promising candidate material for future electrical interconnects in electronics circuits [13].

CNT is a cylindrical configuration made of a single layer of carbon atoms. These CNTs are divided into single-walled CNTs (SWCNTs), Double-walled CNTs (DWCNTs), Tripple-walled CNTs (TWCNTs) and Multi-walled CNTs (MWCNTs). The maximum length to diameter ratio of reported CNT is 132,000,000 to 1 . The diameter of such a long aspect ratio of CNT is in nanometers and the length is in millimetres. The behaviours of CNTs relies upon the aspect ratio, layers, the thickness of layers, temperature, diameter, and length. The tensile strength of nanoscale CNT is higher than steel. The conductivity of CNT is larger than copper. The thermal conductivity of nanoscale CNT is higher than diamond. CNTs can resist corrosion and fatigue [14].

The heat dissipation in the high-density electronic circuits can be diminished by the high thermal conductivity of CNT [15, 16]. The current-density of CNT interconnect is two orders more than $\mathrm{Cu}$ interconnects. This reduces the electro-migration issues, thus increases the reliability [17]. At $25^{\circ} \mathrm{C}$, the SWCNT, MWCNT and $\mathrm{Cu}$ has the mean free path of $10^{3} \mathrm{~nm} 10^{4} \mathrm{~nm}$ and $40 \mathrm{~nm}$ respectively. Thermal conductivity of SWCNT, MWCNT, and $\mathrm{Cu}$ are $1.5-5 \mathrm{~W} / \mathrm{m}-\mathrm{K}, 3 \mathrm{~W} / \mathrm{m}-\mathrm{K}$ and $0.385 \mathrm{~W} / \mathrm{m}-\mathrm{K}$ respectively. CNT has a better mean free path, thermal conductivity and maximum current density than $\mathrm{Cu}$. These attractive properties of CNT make it more suitable for interconnect applications [18].

$\mathrm{Cu}$ and $\mathrm{Al}$ interconnects can be replaced by CNT interconnects in electronic circuits [19, 20]. The crucial problem of heat dissipation in future nanoscale electronics can be considerably reduced by CNT interconnects [21-23]. To obtain the heat dissipation, temperature profiles for the particular power inputs needs to be obtained for interconnects. Finite-element modelling (FEM) can be used to bring out and evaluate the electrothermal performance of 3D CNT interconnects [24-26]. In this paper, FEM based steady-state and transient electrothermal analysis are carried out for $\mathrm{Al}, \mathrm{Cu}$ and $\mathrm{CNT}$ nano electrical interconnects.

\section{Electrical Interconnect}

Electrical interconnects are structures used to connect two or more electrical elements present in the electronic devices and circuits which is shown in Fig. 1. More electrical interconnects can be connected in parallel or used as a bundle to improve the current carrying capability and reliability. The dimension, layers, and material used in the interconnect play a superior part in deciding the proper functioning, reliability and performance parameters. To obtain the performance parameters of the CNT electrical interconnect, steady-state and transient electro-thermal analysis are carried out. The results are compared with $\mathrm{Cu}$ and $\mathrm{Al}$ interconnects. In FEM analysis, CNT electrical interconnects can be considered as a continuum block or continuum shell $[27,28]$.

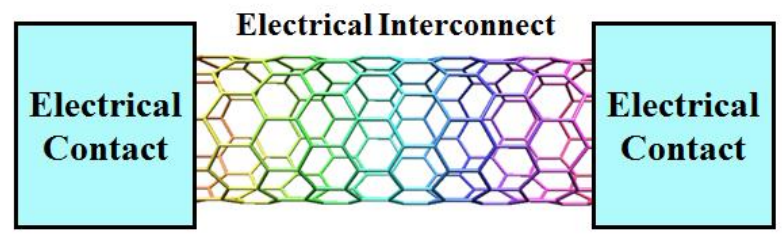

Fig. 1 CNT electrical interconect

CNT interconnects have a cylindrical structure which consists of pentagon rings. The discrete structure of the CNT interconnect is shown in Fig. 2(a). To perform electrothermal analysis and to obtain the performance parameters, CNT 
electrical interconnect is modelled as a continuum solid cylinder block as shown in Fig. 2(b). The interconnect considered in this study has the length of $L$ and the radius of $R$.

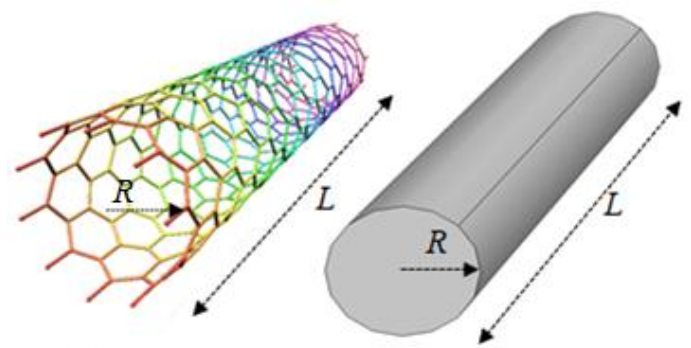

(a)

(b)

Fig. 2 CNT interconect (a) discrete (b) continum solid

The dimensions considered for continuum solid CNT interconnect is $L=100 \mathrm{~nm}$ and $R=2 \mathrm{~nm}$. The electrothermal analysis for interconnects uses the thermal conductivity, density and heat capacity of the materials. The material properties of nanoscale $\mathrm{Al}, \mathrm{Cu}$, and $\mathrm{CNT}$ are obtained from literature and are given in Table 1 .

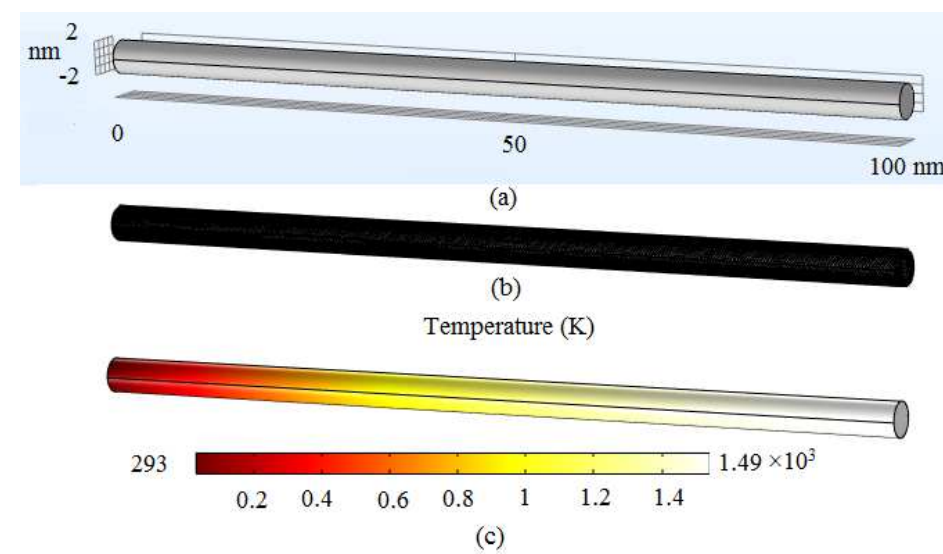

Fig. 3 CNT continum solid interconnect (a) geometry (b) mesh (c) surface temperature

Table. 1 Material Properties [29-33]

\begin{tabular}{|l|c|c|c|}
\hline \multirow{2}{*}{\multicolumn{1}{|c|}{ Property }} & \multicolumn{3}{c|}{ Material } \\
\cline { 2 - 4 } & $\boldsymbol{A} \boldsymbol{l}$ & $\boldsymbol{C} \boldsymbol{C}$ & $\boldsymbol{C N} \boldsymbol{T}$ \\
\hline Thermal conductivty $(\mathrm{W} / \mathrm{m} / \mathrm{K})$ & 237 & 401 & 3000 \\
\hline Density $\left(\mathrm{kg} / \mathrm{m}^{3}\right)$ & 2700 & 8960 & 2100 \\
\hline Heat Capacity $(\mathrm{J} / \mathrm{kg} / \mathrm{K})$ & 904 & 384 & 750 \\
\hline
\end{tabular}

The geometry of the continuum solid CNT interconnect created for the analysis is shown in Fig. 3 (a). As the diameter of the CNT interconnect is much lesser than the length, the heat transfer is considered one-dimensional which is along the length [34]. The one-dimensional heat equation of solids applies to nanoscale interconnects [28]. The FEM analysis solves the following equations to carryout electrothermal analysis and to obtain the performance parameters.

$$
\begin{gathered}
\rho C_{p} . \nabla T+\nabla \cdot q=P \\
q=-k \nabla T
\end{gathered}
$$

where the heat source is power $P$, density is $\rho$, thermal conductivity is $k$, heat capacity is $C_{p}$ and the temperature is $T$. Simulation is carried out with the initial atmospheric temperature of $T_{a t m}=273 \mathrm{~K}$ at one end and heat source at the other end of 
the interconnect. Extremely coarse triangular mesh has been chosen which provides mesh independent results with accuracy. The meshed geometry of the CNT interconnect is given in Fig. 3(b).

In order to validate the simulation results, the calculation is carried out using the relation between power and temperature for cylindrical electrical interconnect which is given as

$$
P=\frac{2 \pi k R^{2}\left(T-T_{a t m}\right)}{L}
$$

Fig. 3(c) indicates the temperature surface plot obtained. The temperature is maximum at the end in which the heat source is provided. This also shows that on the application of $0.9 \mathrm{~mW}$ power, the maximum temperature of $1490 \mathrm{~K}$ appeared at the interconnect. The temperature has been obtained by varying the applied power from $0 \mathrm{~mW}$ to $3 \mathrm{~mW}$ and the effects are shown in Fig. 4. The maximum temperature is estimated based on equation 3. The simulation outcomes are matching with the calculation results. A similar examination is carried out for $\mathrm{Al}$ and $\mathrm{Cu}$ interconnects.

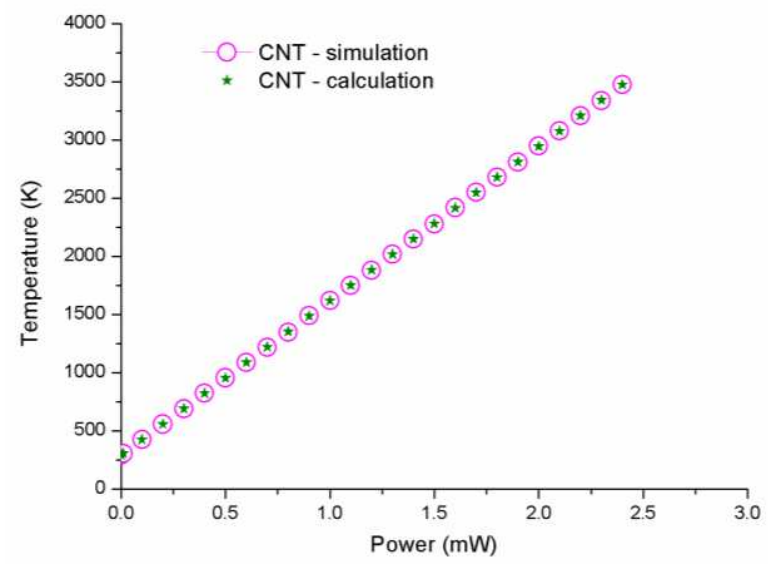

Fig. 4 Power Vs Temperature for CNT interconnect

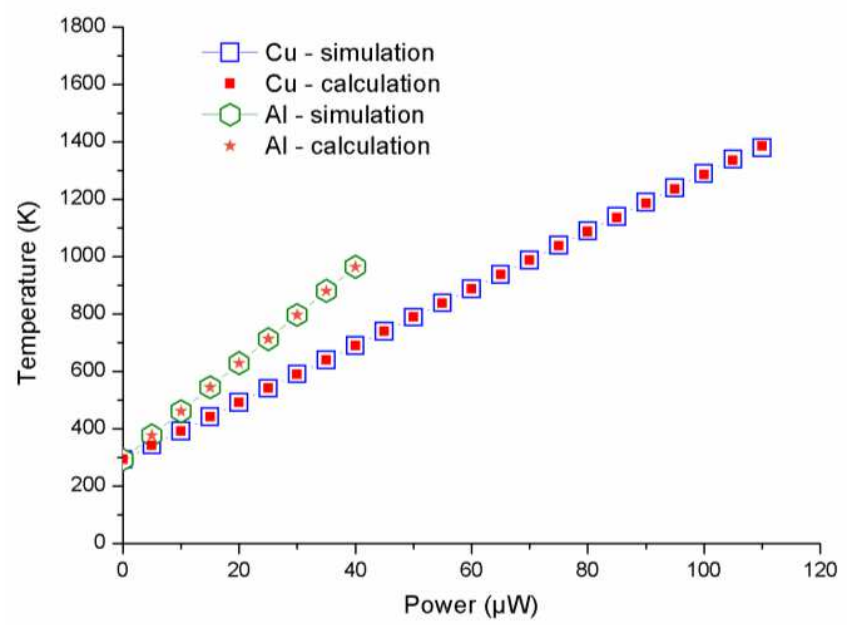

Fig. 5 Temperature as a function of power for $\mathrm{Al}$ and $\mathrm{Cu}$

The power through the interconnect has been varied and the maximum temperature has been obtained for $\mathrm{Al}$ and $\mathrm{Cu}$. The temperature is varied until it reaches the melting temperature of the material. The results obtained from calculation and simulation are shown in Fig. 5. For $\mathrm{Al}$ interconnect, power is varied from 0 to $38 \mu \mathrm{W}$ and for $\mathrm{Cu}$, power has been varied from 0 to $110 \mu \mathrm{W}$. For $\mathrm{Al}$ and $\mathrm{Cu}$ interconnects, the simulated values are in caomparable with the calculated values. The melting temperature of $\mathrm{Al}$ is $933 \mathrm{~K}$. Al interconnect reaches the melting temperature when $38 \mu \mathrm{W}$ power is applied. The melting temperature of copper is $1358 \mathrm{~K}$. The copper interconnect reaches its melting temperature at the power of $110 \mu \mathrm{W}$. So, copper interconnect can withstand 2.9 times more power than $\mathrm{Al}$. Moreover, at a given power, the heat dissipated by $\mathrm{Cu}$ is less when compared to Al. A similar analysis is carried out for CNT interconnects. The heat dissipated for a given power is very less for $\mathrm{CNT}$ than $\mathrm{Cu}$ and $\mathrm{Al}$. 
The melting temperature of the CNT is $3400 \mathrm{~K}$ [35]. CNT interconnect reaches its melting temperature at $2.4 \mathrm{~mW}$. This is 21 times higher than copper. Moreover, the softening point of $\mathrm{Al}$ and $\mathrm{Cu}$ are $423 \mathrm{~K}$ and $463 \mathrm{~K}$ respectively. The thermal stability of $\mathrm{CNT}$ is $700^{\circ} \mathrm{C}(993 \mathrm{~K})[36]$. $\mathrm{Al}$ and $\mathrm{Cu}$ interconnect catches its softening point at the power of $8 \mu \mathrm{W}$ and $17 \mu \mathrm{W}$ respectively. CNT interconnect reaches its stable temperature at the power of $0.55 \mathrm{~mW}$. This shows that for a fixed size of electrical interconnect, CNT interconnect is capable of withstanding more power. This shows that the power withstanding capability of CNT is 68.75 times more than $\mathrm{Al}$ and 32.35 times more than $\mathrm{Cu}$.

\section{Influence of layers on electrotermal parameters of CNT interconnect}

The performance of the interconnect depends on the number of layers present in CNT. Depends on the layers, the CNTs are sorted into Single-Walled CNT (SWCNT), Double-Walled CNT (DWCNT), Triple-Walled CNT(TWCNT) and Multiplewalled CNT (MWCNT) which are displayed in Fig. 6. The cross-sectional outlook of layers of CNT is shown in Fig. 7.

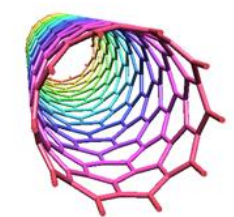

(a)

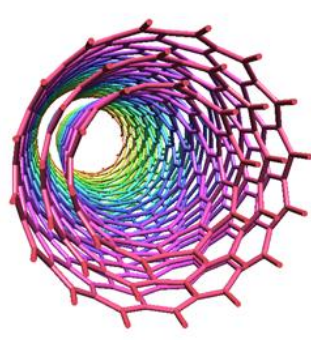

(c)

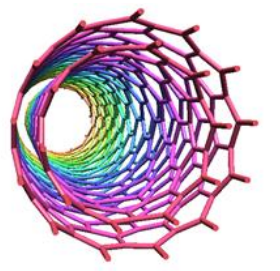

(b)

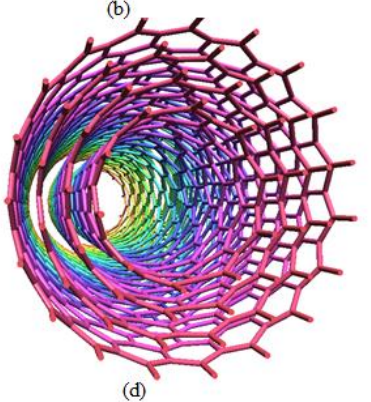

Fig. 6 Layers of CNT (a) SWCNT (b) DWCNT (c) TWCNT (d) MWCNT

Fig. 6 Layers of CNT (a) SWCNT (b) DWCNT (c) TWCNT (d) MWCNT

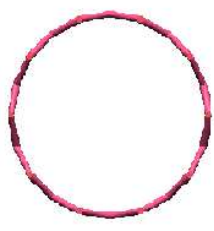

(a)

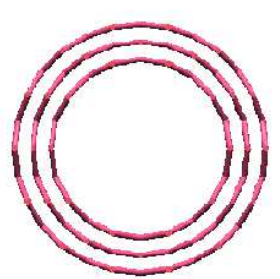

(c)

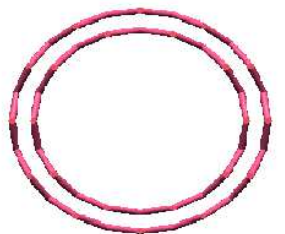

(b)

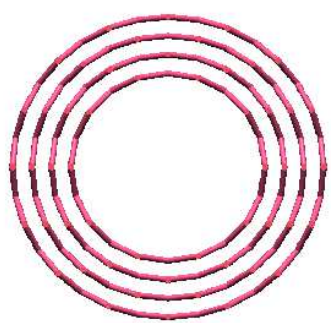

(d)

Fig. 7 Cross sectional view of layers of CNT (a) SWCNT (b) DWCNT (c) TWCNT (d) MWCNT

SWCNT has only one layer. The cross-sectional view of the continuum shell model of SWCNT is displayed in Fig. 8(a). The inner diameter is $r_{1}$ and outer diameter is $r_{2}$. The relation between power and temperature of the SWCNT is given as

$$
P=\frac{2 \pi k\left(r_{2}^{2}-r_{1}^{2}\right)\left(T-T_{a t m}\right)}{L}
$$

The DWCNT has two layers. The cross-sectional view of the continuum shell model of DWCNT is shown in Fig. 8(b). 


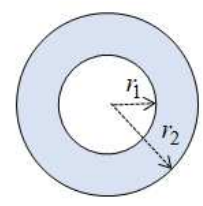

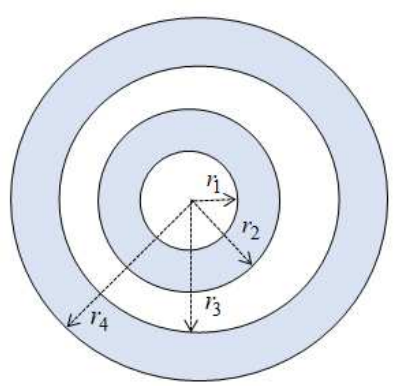

(b)

Fig. 8 Cross section of continum shell (a) SWCNT (b) DWCNT

The relation between temperature and power for DWCNT is given as

$$
P=\frac{2 \pi k\left[\left(r_{2}^{2}-r_{1}^{2}\right)+\left(r_{4}^{2}-r_{3}^{2}\right)\right]\left(T-T_{a t m}\right)}{L}
$$

where $r_{1}$ and $r_{2}$ are the inner radius and outer radius of the interior layer respectively. Similarly, $r_{3}$ and $r_{4}$ are the innerradius and outer radius of the exterior layer.

The TWCNT has three layers. The cross-sectional view of the continuum shell model of TWCNT is shown in Fig.9. The power-temperature relation of TWCNT is given as

$$
P=\frac{2 \pi k\left[\left(r_{2}^{2}-r_{1}^{2}\right)+\left(r_{4}^{2}-r_{3}^{2}\right)+\left(r_{6}^{2}-r_{5}^{2}\right)\right]\left(T-T_{a t m}\right)}{L}
$$

where $r_{1}$ and $r_{2}$ are the inner radius and outer radius of the interior layer respectively. Similarly, $r_{3}$ and $r_{4}$ are the inner and outer radius of the middle layer. $r_{5}$ and $r_{6}$ are the exterior and outer radius of the outer layer.

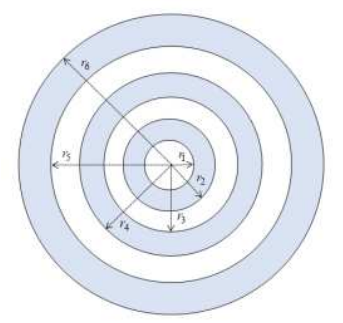

Fig. 9 Cross section a TWCNT

The MWCNT has four or more layers. The cross-sectional view of the continuum shell model of MWCNT is displayed in Fig. 10. The power-temperature relation of four-layer MWCNT is given in equation 7.

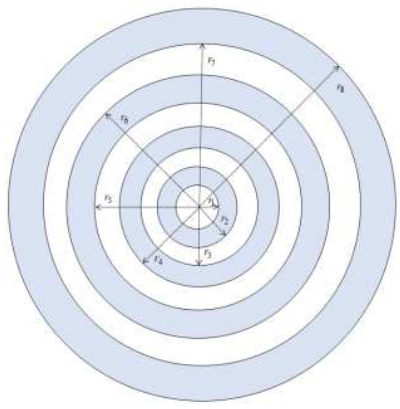

Fig. 10 Cross section MWCNT

$$
P=\frac{2 \pi k\left[\left(r_{2}^{2}-r_{1}^{2}\right)+\left(r_{4}^{2}-r_{3}^{2}\right)+\left(r_{6}^{2}-r_{5}^{2}\right)+\left(r_{8}^{2}-r_{7}^{2}\right)\right]\left(T-T_{a t m}\right)}{L}
$$

where $r_{7}$ and $r_{8}$ are the inner and outer radius of the outermost layer respectively. 
To evaluate the electrothermal performance of the CNT electrical interconnect, the 3D continuum shell model has been constructed in COMSOL simulations. The dimensions considered for this simulation are $r_{1}=1.6 \mathrm{~nm} ; r_{2}=2 \mathrm{~nm} ; r_{3}=2.6 \mathrm{~nm} ; r_{4}=3 \mathrm{~nm} ; r_{5}=3.6 \mathrm{~nm} ; r_{6}=4 \mathrm{~nm} ; r_{7}=4.6 \mathrm{~nm} ; r_{8}=5 \mathrm{~nm}$. The 3D view of the layered CNTs is given in Fig. 11. The meshed structure of layered CNTs is given in Fig. 12. The power of $0.9 \mathrm{~mW}$ is applied on the CNT layers and the temperature distribution is obtained which are given in Fig. 13. At $0.9 \mathrm{~mW}$, the maximum power dissipated by the SWCNT, DWCNT, TWCNT, and MWCNT is $3610 \mathrm{~K}, 1590 \mathrm{~K}, 1000 \mathrm{~K}$, and $745 \mathrm{~K}$ respectively.

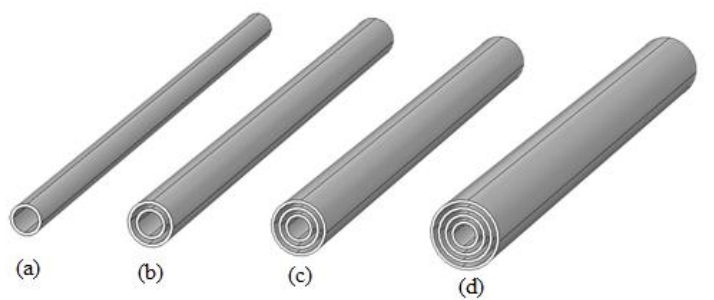

Fig. 11 CNT continum shell (a) SWCNT (b) DWCNT (c) TWCNT (d) MWCNT

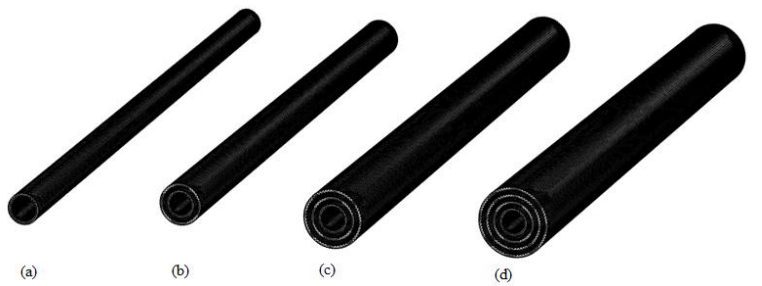

Fig. 12 CNT meshed continum shell (a) SWCNT (b) DWCNT (c) TWCNT (d) MWCNT

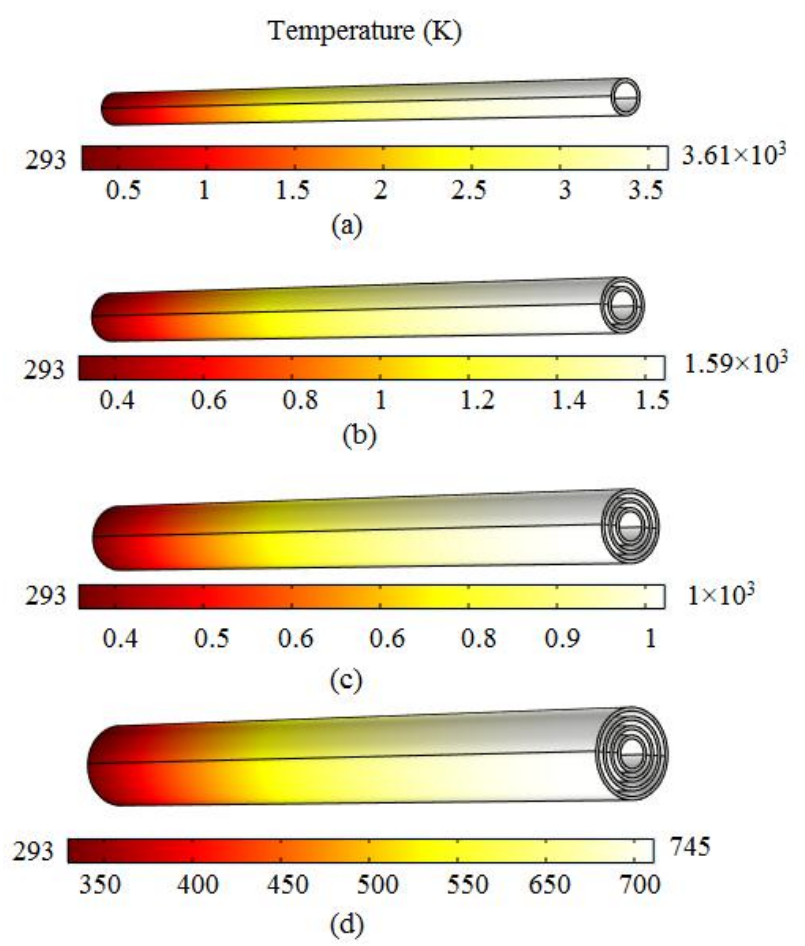

Fig. 13 Temperature distribution (a) SWCNT (b) DWCNT (c) TWCNT (d) MWCNT 


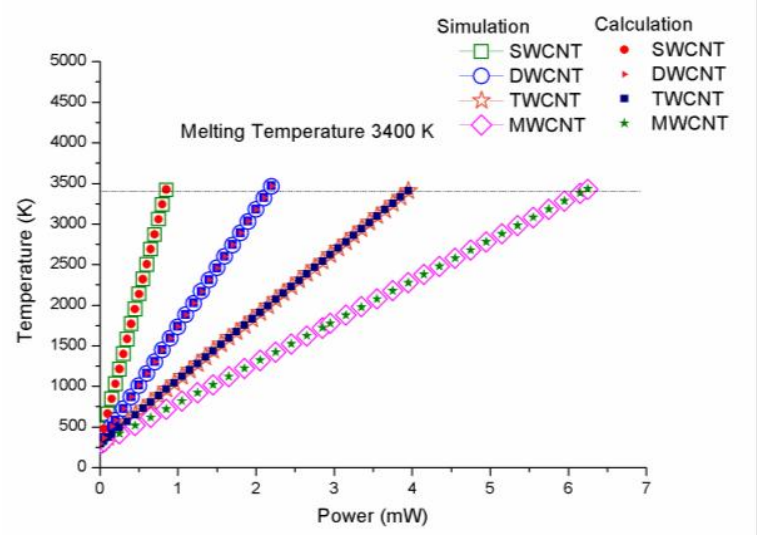

Fig. 14 Temperature as a function of power for layered CNTs

Power applied to the interconnect are varied and the temperature is obtained which is shown in Fig. 14. This shows the calculation and simulation results. The simulated values are matching with the calculated values. The SWCNT, DWCNT, TWCNT, and MWCNT are reaching the melting temperature at $0.85 \mathrm{~mW}, 2.2 \mathrm{~mW}, 3.95 \mathrm{~mW}$ and $6.25 \mathrm{~mW}$ respectively. The SWCNT, DWCNT, TWCNT, and MWCNT are reaching a stable temperature at $0.175 \mathrm{~mW}, 0.48 \mathrm{~mW}, 0.9 \mathrm{~mW}$, and $1.39 \mathrm{~mW}$ respectively. The MWCNT provides better performance than other CNTs because of the increased cross-sectional area.

\section{Transient Temperature of electrical interconnect}

To obtain the time taken by the electrical interconnect to reach the steady-state value, transient analysis has been carried out. For the Al electrical interconnect, the transient temperature characteristics are obtained for $5 \mu \mathrm{W}, 20 \mu \mathrm{W}$, and $38 \mu \mathrm{W}$. The transient characteristics curve is shown in Fig. 15. This shows that Al electrical interconnect reaches a steady-state temperature at $0.1 \mathrm{~ns}$.

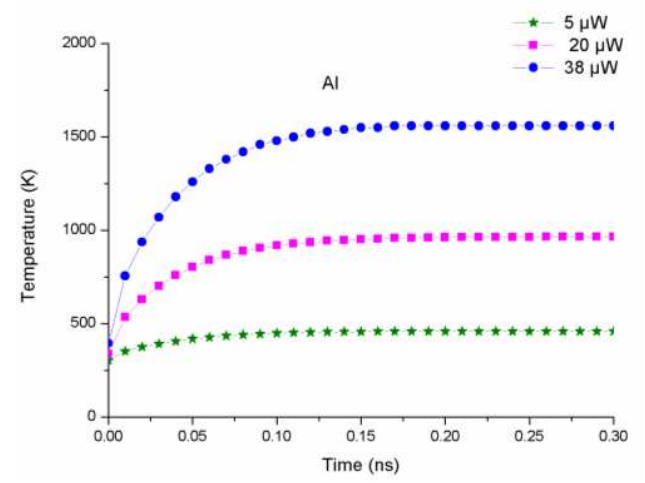

Fig. 15 Transient temperature for $\mathrm{Al}$ interconnect

For $\mathrm{Cu}$ electrical interconnect, the transient temperature characteristics are obtained for $50 \mu \mathrm{W}, 80 \mu \mathrm{W}$ and $110 \mu \mathrm{W}$ which are shown in Fig. 16. This shows that the $\mathrm{Cu}$ electrical interconnect also reaches a steady-state temperature at $0.1 \mathrm{~ns}$.

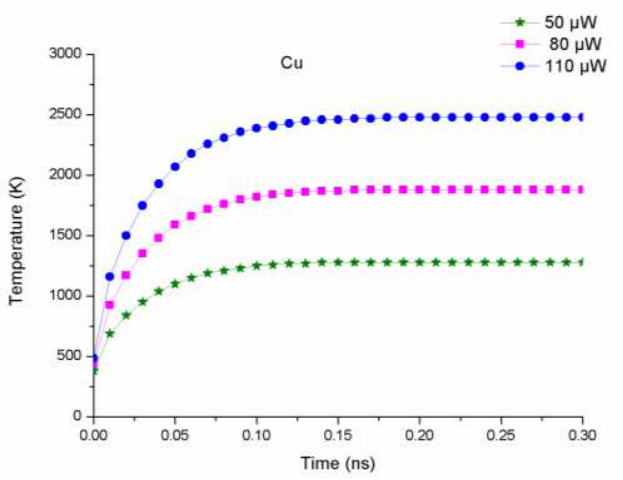

Fig. 16 Transient temperature for $\mathrm{Cu}$ interconnect

For CNT interconnect, the transient temperature characteristics are obtained for $0.5 \mathrm{~mW}, 1.5 \mathrm{~mW}$ and $2.4 \mathrm{~mW}$ which are shown in Fig. 17. This shows that for the CNT electrical interconnect, the temperature reaches a steady value at $0.007 \mathrm{~ns}$. 


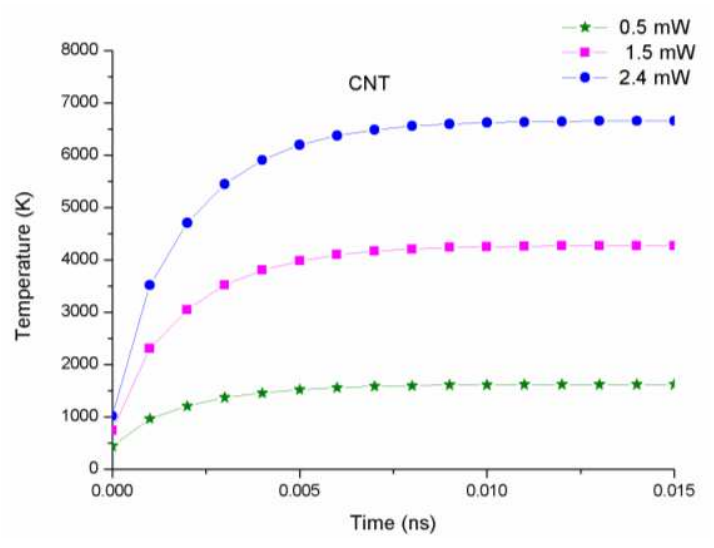

Fig. 17 Transient temperature for CNT

Transient temperature analysis is carried out for SWCNT, DWCNT, TWCNT, and MWCNT. The transient thermal characteristics for the power of $0.9 \mathrm{~mW}$ given for layered CNTs in Fig. 18. This also shows that CNT electrical interconnects reaches a steady temperature at $0.007 \mathrm{~ns}$. This means after reaches a steady-state, the layers can not absorb heat. It is observed that CNT interconnects reaches a steady temperature faster than $\mathrm{Al}$ and $\mathrm{Cu}$.

Lower density and specific heat of CNT tend to reduce the time constant thus reaches the steady-state temperature faster. The high heat transfer coefficient also reduces the time constant. All these results show that CNTs would be a better material for electrical interconnects when compared to $\mathrm{Al}$ and $\mathrm{Cu}$. In layered $\mathrm{CNT}$, MWCNT performs better for electrical interconnect applications at the nanoscale.

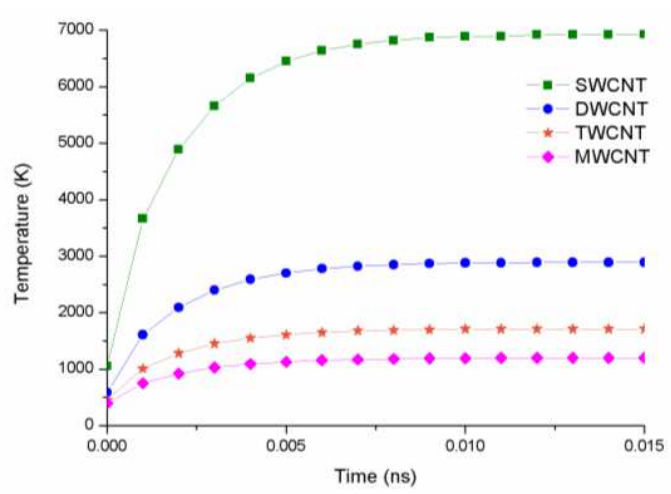

Fig. 18 Transient temperature for SWCNT, DWCNT, TWCNT and MWCNT

\section{Discussion}

When $\mathrm{Al}$ and $\mathrm{Cu}$ metal electrical interconnects scale down below $100 \mathrm{~nm}$ for micro and nanoelectronic devices, faces many challenges. The lateral dimension of the interconnect is near to the mean free path of material, the resistivity of the material increases rapidly. This is due to the surface scattering, boundary scattering, and diffusive barrier layer. The nanoscale metal interconnects behaves differently than a millimetre and micro-scale metal electrical interconnects. The outstanding potential and extraordinary properties of CNTs have attracted interest among various researchers and can be used in future electrical interconnects. In this work, the thermal conductivity of CNT is considered as $3000 \mathrm{~W} / \mathrm{m} \mathrm{K}$. But in practice, the thermal conductivity of CNT depends on length, area of cross-section, diameter, number of layers and thickness of each layer. The experimental results from the literature show that the thermal conductivity of CNTs deviates in large from 20 to $3000 \mathrm{~W} / \mathrm{m} \mathrm{K}$. Also, because of the inter-wall van der Waals interactions, the thermal conductivity of MWCNTs decreases considerably when compared to SWCNTs. In addition to this, the thermal conductance of MWCNT considerably larger than SWCNT. In MWCNT, the outer tube has an influential role in heat energy transfer. The thermal conductivity of CNTs is highly complex and nonlinear which are a function of diameter, length and temperature [37-39]. MWCNTs and Mixed Carbon Nanotube bundles (MCBs) can increase the performance and reliability of interconnects in deep sub-micron (DSM) region for VLSI-Ic devices. These MWCNTs and MCBs provide better performance for a wide range of temperature ranges between 200 to 450 $\mathrm{K}$ at the technology node size varies from $32 \mathrm{~nm}$ to $14 \mathrm{~nm}$ [40, 41]. Although CNT interconnects provide better performance in theoretical and simulation research, fabrication of CNT electrical interconnects for practical applications remains challenging. More technological development and research are still required [42, 43]. 
CNT bundles are a suitable candidate for power interconnects. In future, CNTs would be used as an attractive material for VLSI device components. CNT and graphene-based hybrid materials and composite materials would be given more priority in optoelectronic devices, electrical contacts, interconnects, sensors, and circuits [44-47]. Even though CNTs shows promising results for electrical interconnect applications, full implementation of these CNT electrical interconnects in electronic circuits, and Integrated circuits (IC) would take another few years.

\section{Conclusion}

CNT based electrical interconnects have huge potential and extraodinary properties to replace presently used $\mathrm{Cu}$ and $\mathrm{Al}$ interconnects in electronic devices. This paper presents the finite element method based electrothermal analysis for CNT based electrical interconnects. The temperature for the given power is obtained for CNT, Al, and $\mathrm{Cu}$. The results show that the CNT interconnects perform better than $\mathrm{Al}$ and $\mathrm{Cu}$. Also, electrothermal analysis is carried out for SWCNT, DWCNT, TWCNT, and MWCNT. The power withstanding capability of CNT is 32.35 times more than $\mathrm{Cu}$ and 68.75 times more than Al. In addition to this CNT has more tensile strength and lightweight. The time taken by the CNT to reach a steady temperature is $0.007 \mathrm{~ns}$. Hence, CNT would be the most preferred material choice for electrical interconnects for future electronic devices and circuits.

\section{Aknowledgement}

The author acknowledges BITS-Pilani K. K. Birla Goa Campus for providing access to COMSOL Multiphysics Finite Element software.

\section{References}

[1] G. E. Moore, Cramming more components onto integrated circuits, Electronics. 38 (1965) 114-117. DOI: 10.1109/NSSC. 2006.4785860

[2] International Technology Roadmap for Semiconductors, Edition 2013. Available online: http://www.itrs2.net/ .Accessed on 16 November 2020.

[3] K. Banerjee, S. J. Souri, P. Kapur, K. C. Saraswat, A novel chip design for improving deep-submicrometer interconnect performance and systems-on-chip integration, Proc. IEEE89 (2001), 602-633. DOI: 10.1109/5.929647

[4] J. A. Davis, R. Venkatesan, A. Kaloyeros, M. Beylansky, S. J. Souri, K. Banerjee, K. C. Saraswat, A. Rahman, R. Reif, and J. D. Meindl, Interconnect limits on gigascale integration (GSI) in the 21st century, Proc. IEEE, 89 (2001) 305-324, 2001. DOI: $10.1109 / 5.915376$

[5] S. Chaudhary, S. A. Nair, F. T. Nyamsi, M. Schulz, M. Rabiee, and M. Cahay, Emerging Applications of Carbon Nanotube Wires in Electromagnetic Machines, International Journal of Energy. 12 (2018) $26-31$. https://www.naun.org/main/NAUN/energy/2018/a102009-070.pdf

[6] R. Zhang, K. Yang, E. Metaev, M. Pesic, J. Lloyd, M. Ring, P. Paliwoda, S. Tan, C. Young and G. Verzellsi, Reliability and modeling: What to simulate and how?, In Proceedings of the Invited IEEE International Integrated Reliability Workshop (IEEE IIRW)., (2017) 8-12. DOI: 10.1109/IIRW.2017.8361248

[7] B. Li, T. D. Sullivan, T. C. Lee, D. Badami, Reliability challenges for copper interconnects, Microelectron. Reliab. 44 (2004) 365-380. https://doi.org/10.1016/j.microrel.2003.11.004

[8] T. P. Dash, S. Dey, J. Jena, S. Das, E. Mohapatra, C. K. Maiti, Metal Grain Granularity Induced Variability in Gate-AllAround Si-Nanowire Transistors at 1nm Technology Node, Devices for Integrated Circuit (DevIC) (2019) $286-290$. DOI: 10.1109/DEVIC.2019.8783717

[9] K. Y. Sung, L. Hyun, K. Yoon; K. Garam, K. J. Hyun, K. Sangwan, Surrounding Channel Nanowire Tunnel FieldEffect Transistor with Dual Gate to Reduce a Hump Phenomenon, J. Nanosci. Nanotechnol. 20 (2020) 4182-4187. DOI: $10.1166 /$ jnn.2020.17793

[10] C. Soldano, S. Talapatra and S. Kar, Carbon Nanotubes and Graphene Nanoribbons: Potentials for Nanoscale Electrical Interconnects, Electronics. 2 (2013) 280-314. https://doi.org/10.3390/electronics2030280

[11] S. Iijima, Helical microtubules of graphitic carbon, Nature. 354 (1991) 56-58. https://doi.org/10.1038/354056a0

[12] L. Kurzepa, A. Lekawa-raus, J. Patmore, and K. Koziol, Replacing Copper Wires with Carbon Nanotube Wires in Electrical Transformers, Advanced Functional Materials. 24 (2014) 619-624. https://doi.org/10.1002/adfm.201302497

[13] A. Lekawa-raus, J. Patmore, L. Kurzepa, and J. Bulmer, "Electrical Properties of Carbon Nanotube Based Fibers and Their Future Use in Electrical Wiring, Advanced Functional Materials. 24 (2014) 3661-3682.

https://doi.org/10.1002/adfm.201303716 
[14] Can Carbon Nanotubes Replace Copper? https://www.assemblymag.com/articles/93180-can-carbon-nanotubes-replacecopper .Accessed on 16 December 2020.

[15] A. Lekawa-raus, J. Patmore, L. Kurzepa, and J. Bulmer, Electrical Properties of Carbon Nanotube Based Fibers and Their Future Use in Electrical Wiring, Advanced Functional Materials. 24 (2014) 3661-3682. https://doi.org/10.1002/adfm.201303716

[16] A. A. Balandin, S. Ghosh, W. Bao, I. Calizo, D. Teweldebrhan, F. Miao and C. N. Lau, Superior thermal conductivity of single-layer graphene, Nano Lett. 8, (2008) 902-907. https://doi.org/10.1021/n10731872

[17] S. Berber, Y. K. Kwon and D. Tomanek, Unusually high thermal conductivity of carbon nanotubes, Phys. Rev. Lett. 84 (2000) 4613. https://doi.org/10.1103/PhysRevLett.84.4613

[18] H. Li, W. Liu, A. M. Cassell, F. Kreupl, and K. Banerjee, Low-Resistivity Long- Length Horizontal Carbon Nanotube Bundles for Interconnect Applications — Part I : Process Development, IEEE Trans. Electron Devices. 60 (2013) 28622869. DOI: 10.1109/TED.2013.2275259

[19] B. Q. Wei, R. Vajtai, and P. M. Ajayan, Reliability and current carrying capacity of carbon nanotubes, Appl. Phys. Lett. 79 (2001) 1172-1174. https://doi.org/10.1063/1.1396632

[20] E. Pop, D. Mann, J. Reifenberg, and H. Dai, Electro-thermal transport in metallic single-wall carbon nanotubes for interconnect applications, IEDM Tech. Dig. (2005) 253-256. DOI: 10.1109/IEDM.2005.1609321

[21] H. Li, C. Xu, N. Srivastava and K. Banerjee, Carbon nanomaterials for next-generation interconnects and passives: Physics, status, and prospects, IEEE Trans. Electron. Devices. 56 (2009) 1799-1821. DOI: 10.1109/TED.2009.2026524

[22] A. G. Chiariello, A. Maucci, and G. Miano, Circuit models of carbon-based interconnects for nanopackaging, IEEE Trans. Compon. Packag. Manuf. Technol. 3 (2013) 1926-1937. DOI: 10.1109/TCPMT.2013.2262213

[23] W. S. Zhao and W. Y. Yin, Carbon-based interconnects for RF nanoelectronics, Wiley Encycl. Electr. Electron. Eng. (2012) 1-20. https://doi.org/10.1002/047134608X.W8147

[24] N. Li, J. Mao, W. S. Zhao, M. Tang, W. Chen and W. Y. Yin, Electrothermal cosimulation of 3-D carbon-based heterogeneous interconnects, IEEE Trans. Compon. Packag. Manuf. Technol. 6 (2016) 518-526. DOI: 10.1109/TCPMT.2016.2538298

[25] F. Robert, Prediction of contact length, contact pressure and indentation depth of Au/carbon nanotube composite micro electrical contact using finite element modelling, Applied Surface Science. 489 (2019) 470-476. https://doi.org/10.1016/j.apsusc.2019.05.169

[26] F. Robert, A. Sharma, H. Katare and A. R. J. Fredo, Investigation of graphene as a material for electrical contacts in the application of microrelays using finite element modelling, Mater. Res. Express. 6 (2019) 094008. https://doi.org/10.1088/2053-1591/ab3085

[27] S. A. Selvin, S. A. Lovelin, N. B. Moorthy, A. Gupta, M. Alagappan, Design and Simulation of Carbon Nanotube based Piezoresistive Pressure sensor, Proceedings of COMSOL conference, (2011). https://www.comsol.es/paper/download/84139/s_paper.pdf

[28] M. Tahani, M.H. Abolbashari, S.T. Talebian, B. Mehrafrooz, H. Saberi Nik, Transient heat conduction in multiwall carbon nanotubes, Lat. Am. j. solids struct. 12 (2015) 711-729. https://doi.org/10.1590/1679-78251374

[29] N. R. Pradhan, H. Duan, J. Liang and G. S. Iannacchione, The specific heat and effective thermal conductivity of composites containing single-wall and multi-wall carbon nanotubes, Nanotechnology. 20 (2009), 245705. DOI: $10.1088 / 0957-4484 / 20 / 24 / 245705$

[30] Copper nanowires, Product datasheet. Available online: https://www.americanelements.com/copper-nanowires-744050-8. Accessed on 27 November 2020.

[31] Aluminum nanowires, Product datasheet. Available online: https://www.americanelements.com/aluminum-nanowires7429-90-5. Accessed on 27 November 2020)

[32] Multi-walled carbon nanotubes, Product data sheet. Available online: https://www.americanelements.com/multi-walledcarbon-nanotubes-308068-56-6. Accessed on 28 October 2020)

[33] W. Zhao, K. Fu, D. WeiWang, M. Li, G. Wang and W. Yin, Mini-Review: Modeling and Performance Analysis of Nanocarbon Interconnects, Appl. Sci. 9 (2019) 2174. https://doi.org/10.3390/app9112174

[34] C. Li, S. Xu, Y. Yue, B. Yang, X. Wang, Thermal characterization of carbon nanotube fiber by time-domain differential Raman, Carbon. 103 (2016) 101-108. https://doi.org/10.1016/j.carbon.2016.03.003

[35] X. Wei, M. Wang, Y. Bando and D. Golberg, Thermal stability of carbon nanotubes probed by anchored tungsten nanoparticles, Sci. Technol. Adv. Mater.12 (2011) 044605. DOI: 10.1088/1468-6996/12/4/044605

[36] K. Doudrick, P. Herckes and P. Westerhoff, Detection of Carbon Nanotubes in Environmental Matrices Using Programmed Thermal Analysis, Environ Sci Technol. 46 (2012) 12246-12253. https://doi.org/10.1021/es300804f 
[37] D. J. Yang, Q. Zhang, G. Chen, S. F. Yoon, J. Ahn, S. G. Wang, Q. Zhou, Q. Wang, and J. Q. Li, Thermal conductivity of multiwalled carbon nanotubes, Physical Review. B 66 (2002) 165440. DOI:10.1103/PhysRevB.66.165440

[38] H. Zhan, J. M. Bell and Y. Gu, Carbon Nanotube-based Super Nanotube: Tailorable Thermal Conductivity at Threedimensional, RSC Adv. 5 (2015) 48164. DOI:10.1039/C5RA05584A

[39] X.Zhang, W. Zhou, X. Chen, Y. Liu, K. Chen, Significant decrease in thermal conductivity of multi-walled carbon nanotube induced by inter-wall van der Waals interactions, PhysicsLetters. A380(2016)1861-1864. https://doi.org/10.1016/j.physleta.2016.03.040

[40] P. K. Jindal and K. S. Sandha, Influence of variable temperature on performance of mixed-MWCNT, MWCNT and SWCNT nanostructures as interconnects for high-performance VLSI-IC design, J Mater Sci: Mater Electron (2020) 31:1828-1838. https://doi.org/10.1007/s10854-019-02699-7

[41] M. Sharma, M. K. Rai and R. Khanna, Performance analysis of irradiation induced defected mixed CNT bundle based coupled VLSI interconnects. J Mater Sci: Mater Electron. (2020) 31:21569-21582. https://doi.org/10.1007/s10854-02004670-3

[42] H. Li, W. Liu, A. M. Cassell, F. Kreupl, and K. Banerjee, Low-Resistivity Long-Length Horizontal Carbon Nanotube Bundles for Interconnect Applications — Part I : Process Development, IEEE Trans. Electron Devices. 60 (2013) 28622869. DOI: 10.1109/TED.2013.2275259

[43] N. Srivastava, H. Li, F. Kreupl and K. Banerjee, On the Applicability of Single-Walled carbon Nanotubes as VLSI Interconnects, IEEE Transactions on Nanotechnology. 8 (2009) 542-559. DOI: 10.1109/TNANO.2009.2013945

[44] D. Fathi and B. Forouzandeh, Interconnect Challenges and Carbon Nanotube as Interconnect in Nano VLSI Circuits, Carbon Nanotubes. (2010) 275-297. DOI: 10.5772/39430

[45] J. A. Desai, S. Chugh, M. Michel, A. B. Kaul, Inkjet printed graphene as an interconnect for optoelectronic devices, J Mater Sci: Mater Electron (2019) 30:12500-12509. https://doi.org/10.1007/s10854-019-01610-8

[46] F. Robert Investigation on Graphene-Coated Silver-Palladium Microelectrical Contact and Effect of Coating Thickness, IEEE Trans Compon Packaging Manuf Technol. (2020) 10:1821-1828. DOI: 10.1109/TCPMT.2020.3027565

[47] R. V. Bernal and G. H. Pérez, Carbon Nanotube- and Graphene Based Devices, Circuits and Sensors for VLSI Design, VLSI Design. (2012) 41-66.DOI: 10.5772/38743 
Figures

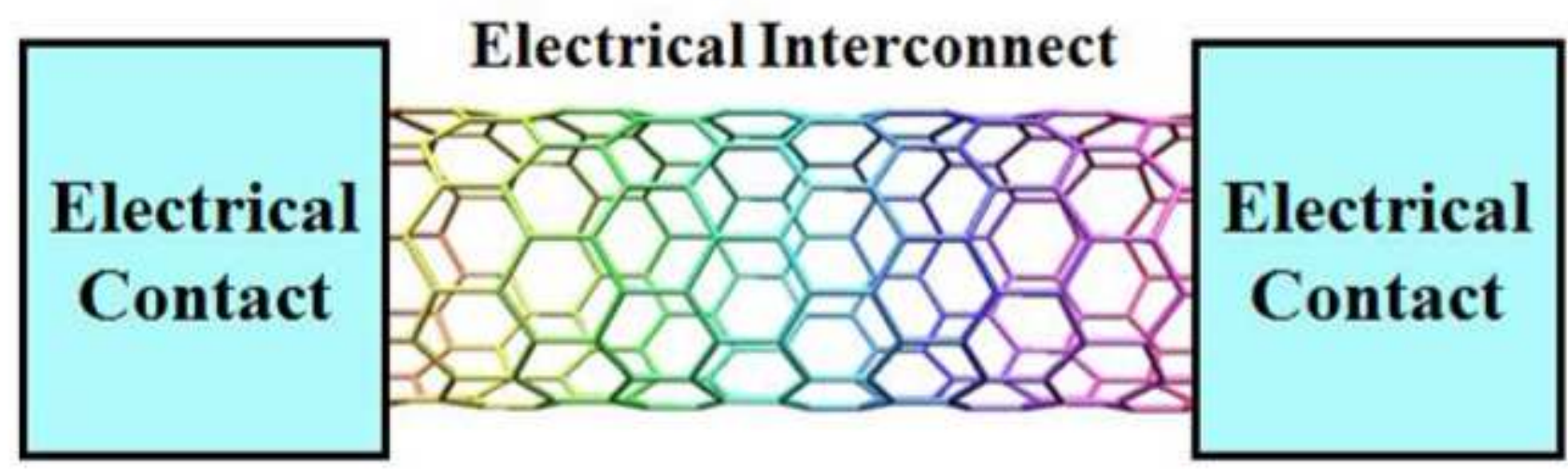

Figure 1

CNT electrical interconect

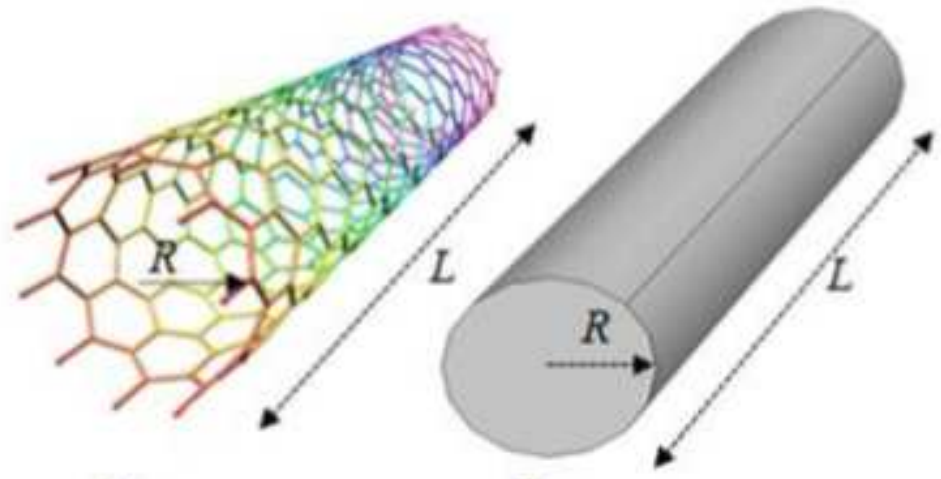

(a)

(b)

Figure 2

CNT interconect (a) discrete (b) continum solid 


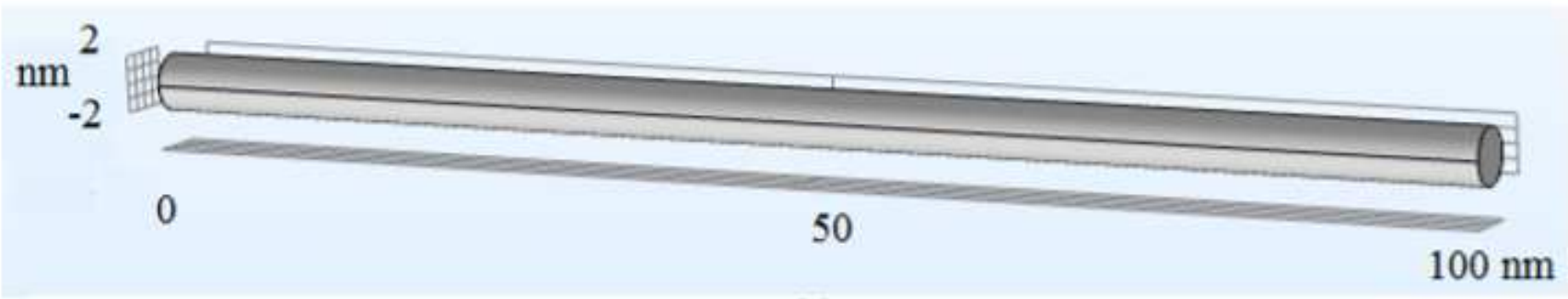

(a)

(b)

Temperature $(\mathrm{K})$

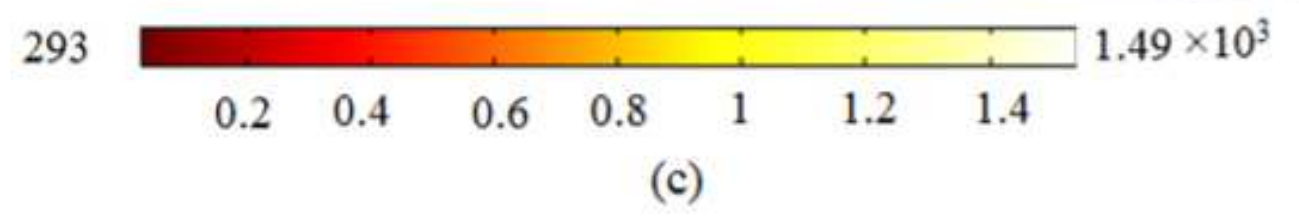

\section{Figure 3}

CNT continum solid interconnect (a) geometry (b) mesh (c) surface temperature 


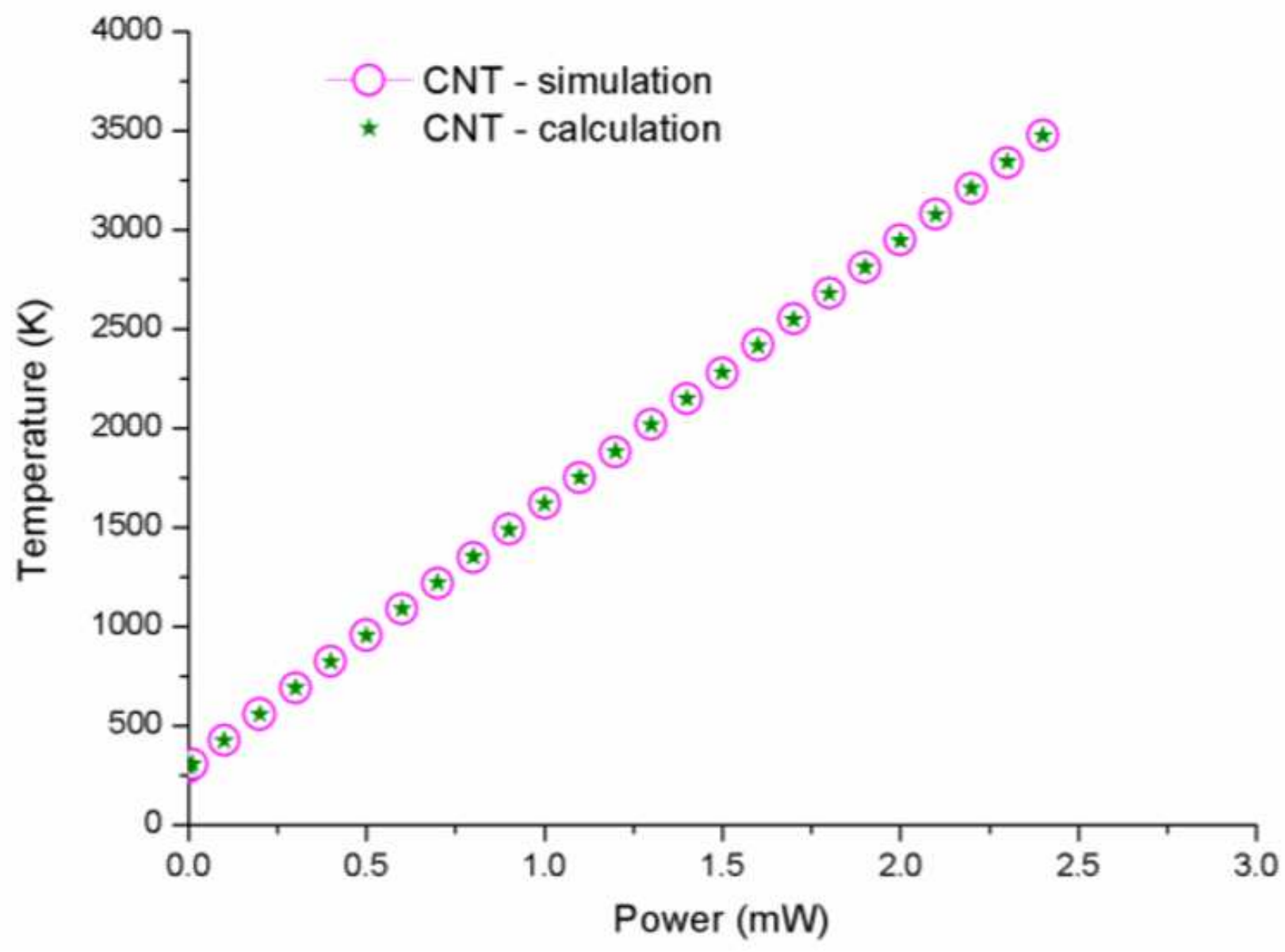

Figure 4

Power Vs Temperature for CNT interconnect 


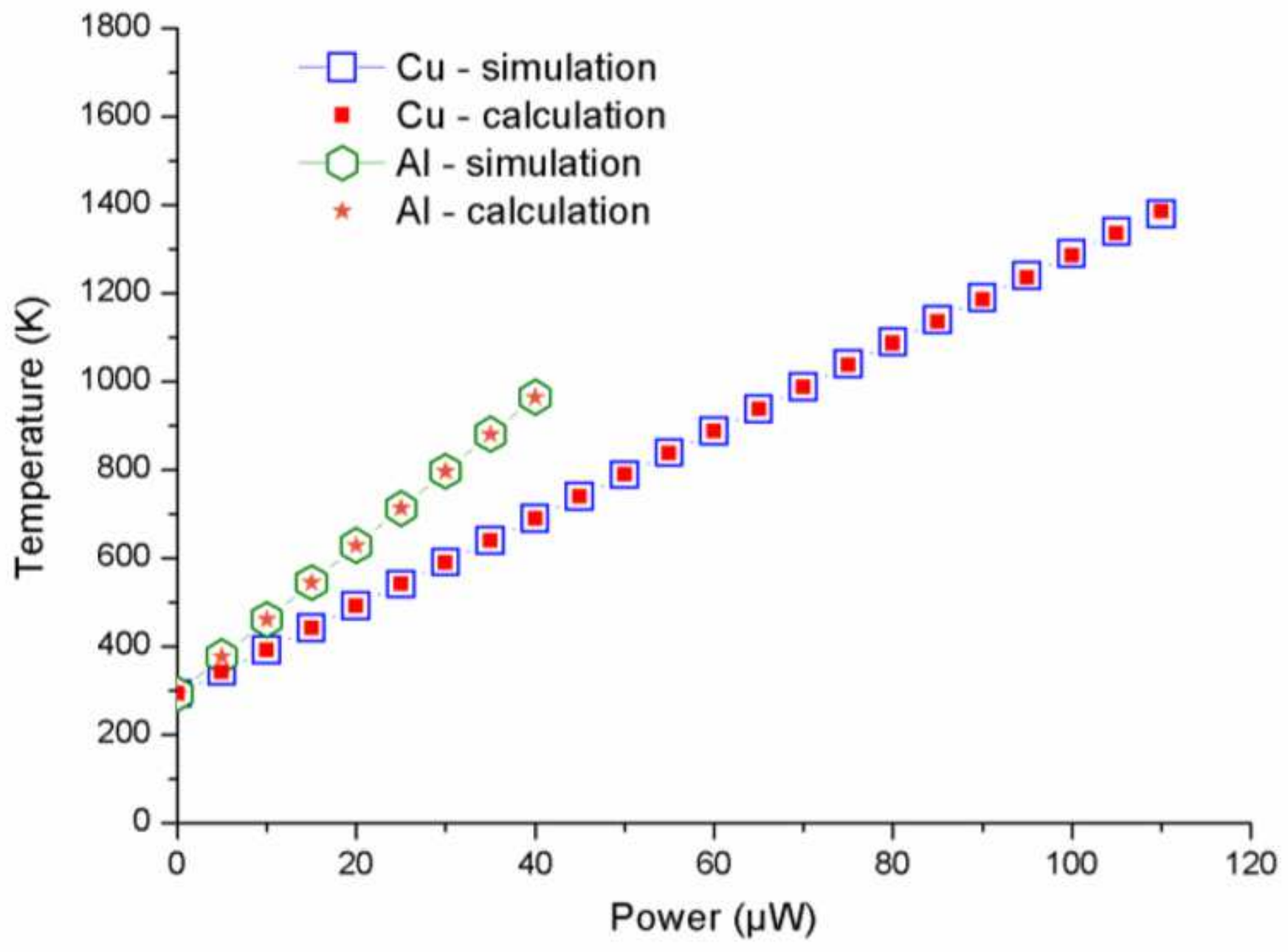

Figure 5

Temperature as a function of power for $\mathrm{Al}$ and $\mathrm{Cu}$ 


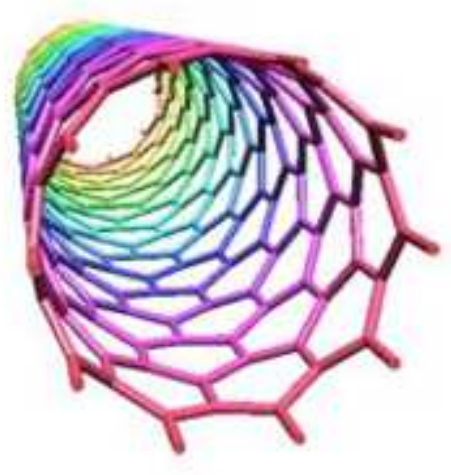

(a)

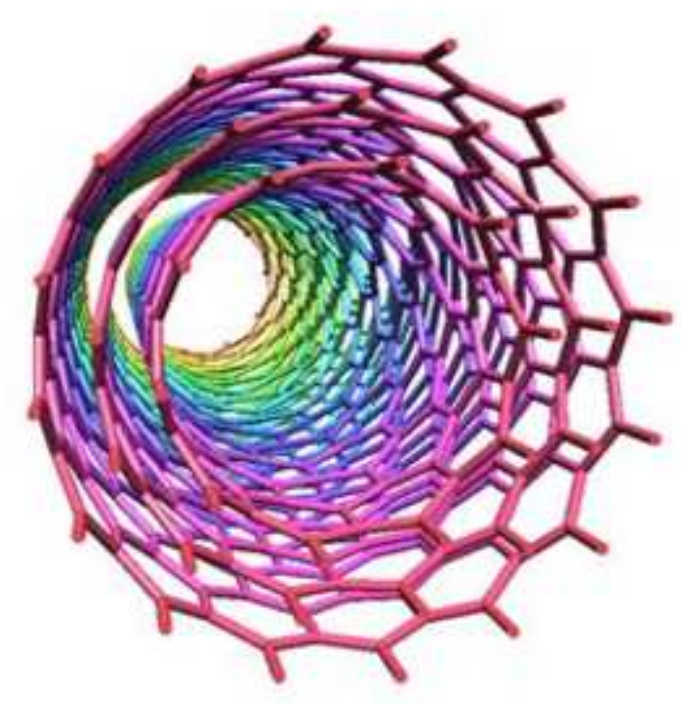

(c)

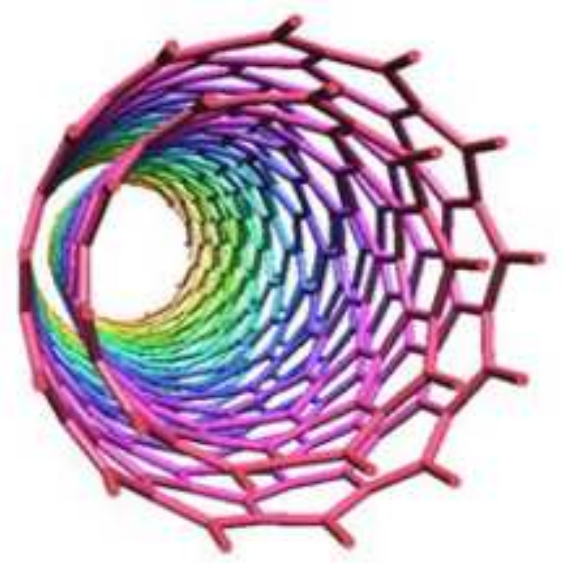

(b)

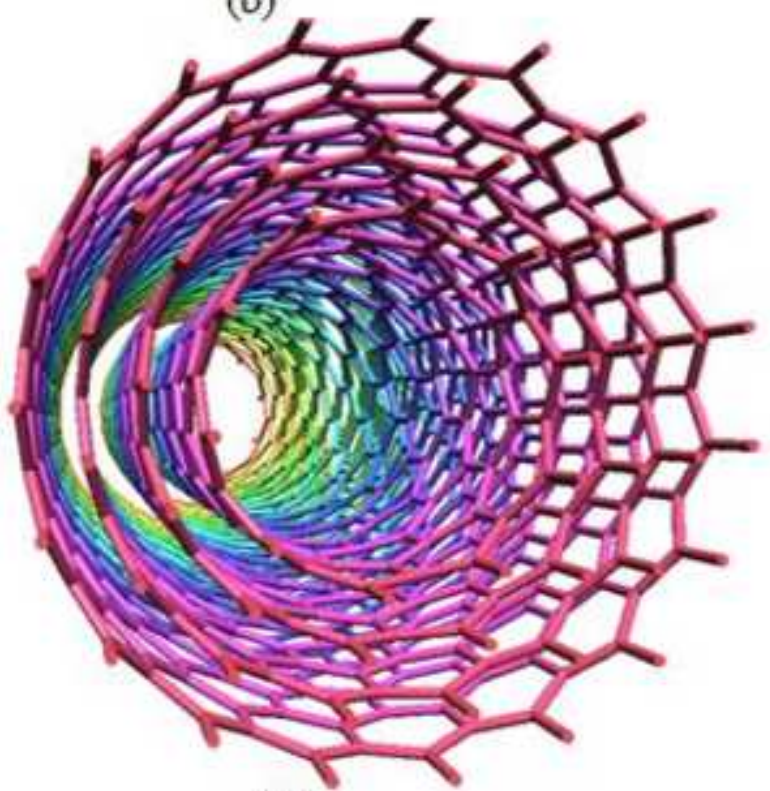

(d)

Figure 6

Layers of CNT (a) SWCNT (b) DWCNT (c) TWCNT (d) MWCNT 


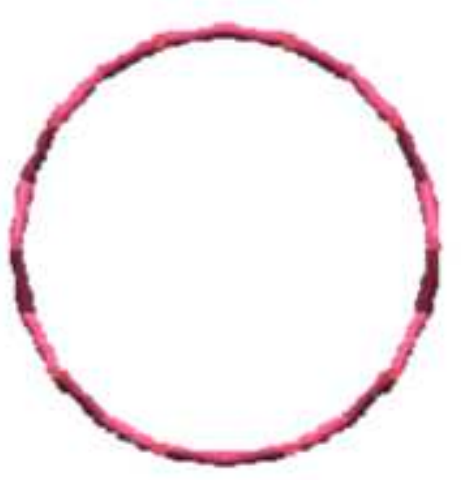

(a)

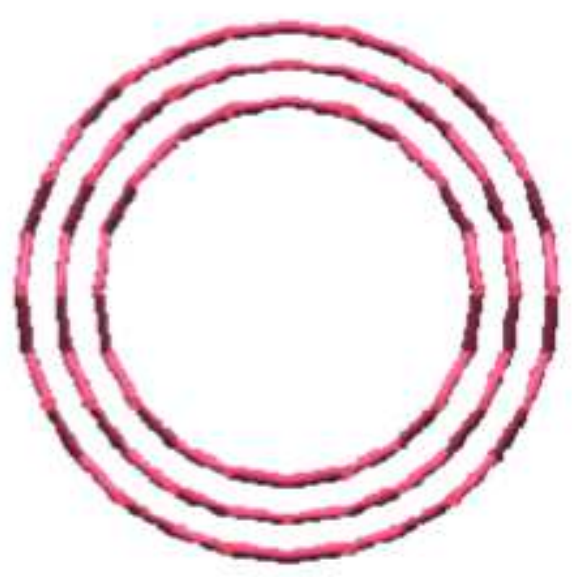

(c)

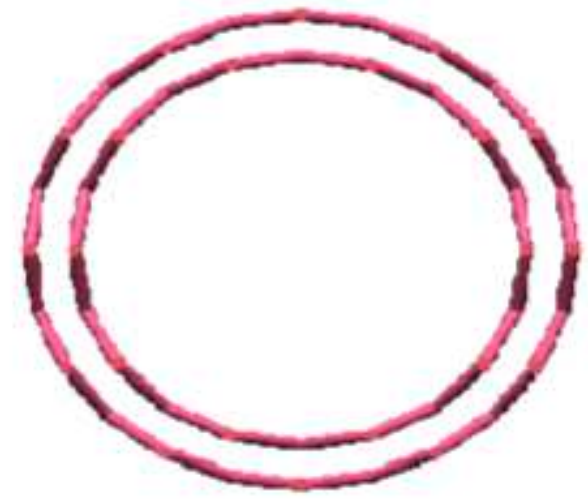

(b)

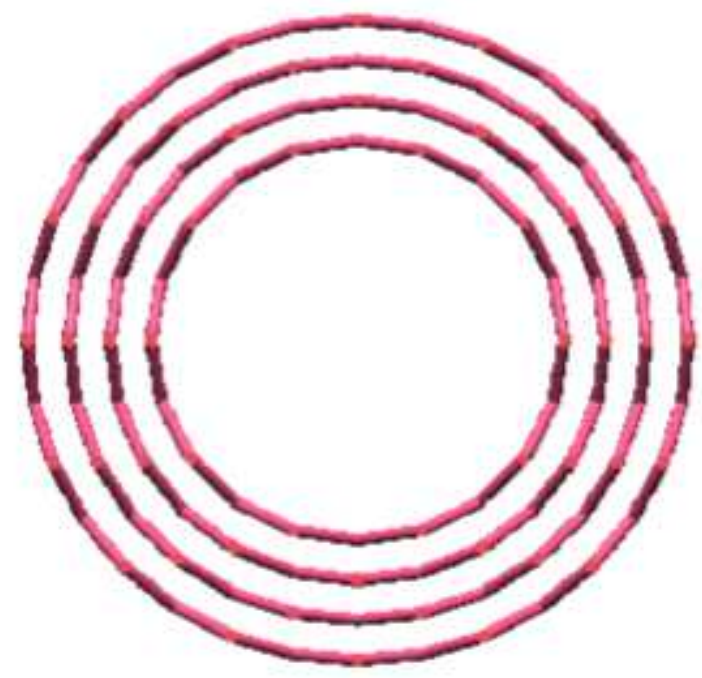

(d)

Figure 7

Cross sectional view of layers of CNT (a) SWCNT (b) DWCNT (c) TWCNT (d) MWCNT 

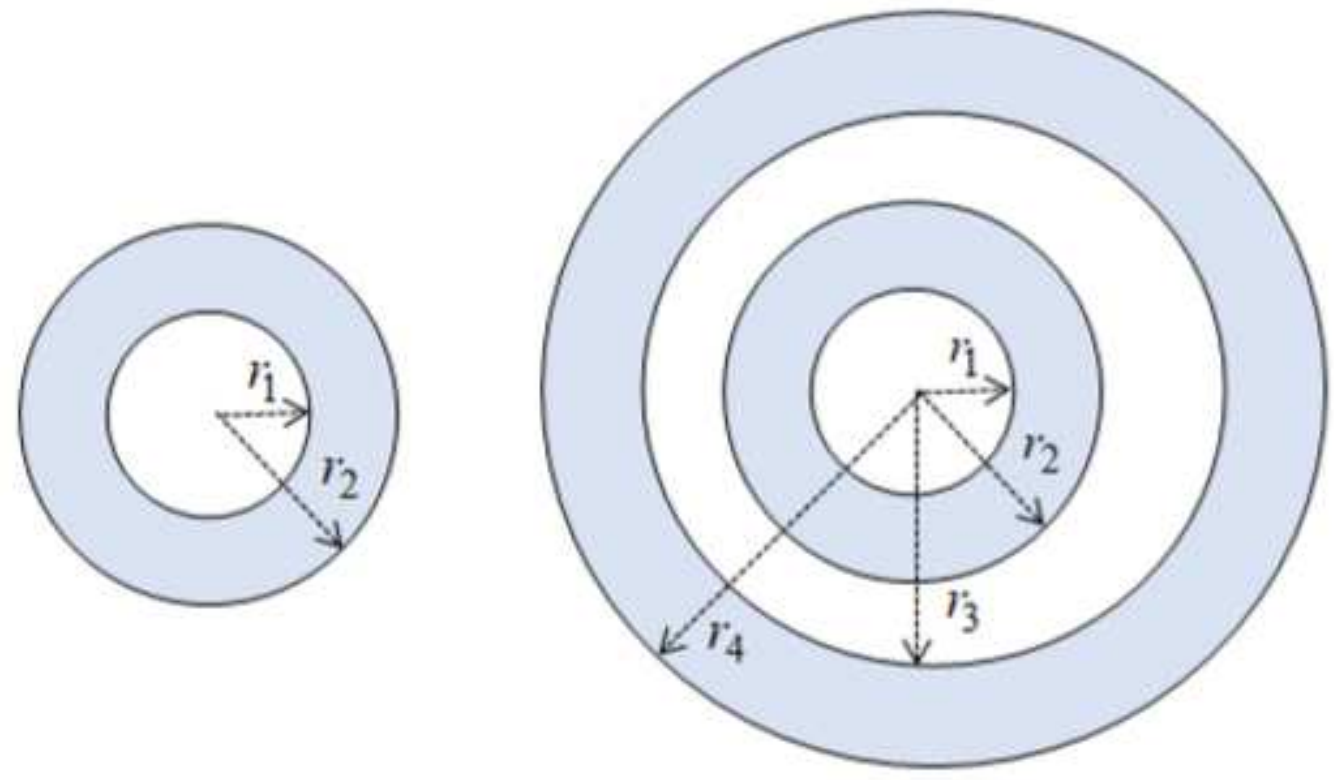

(a)

(b)

Figure 8

Cross section of continum shell (a) SWCNT (b) DWCNT

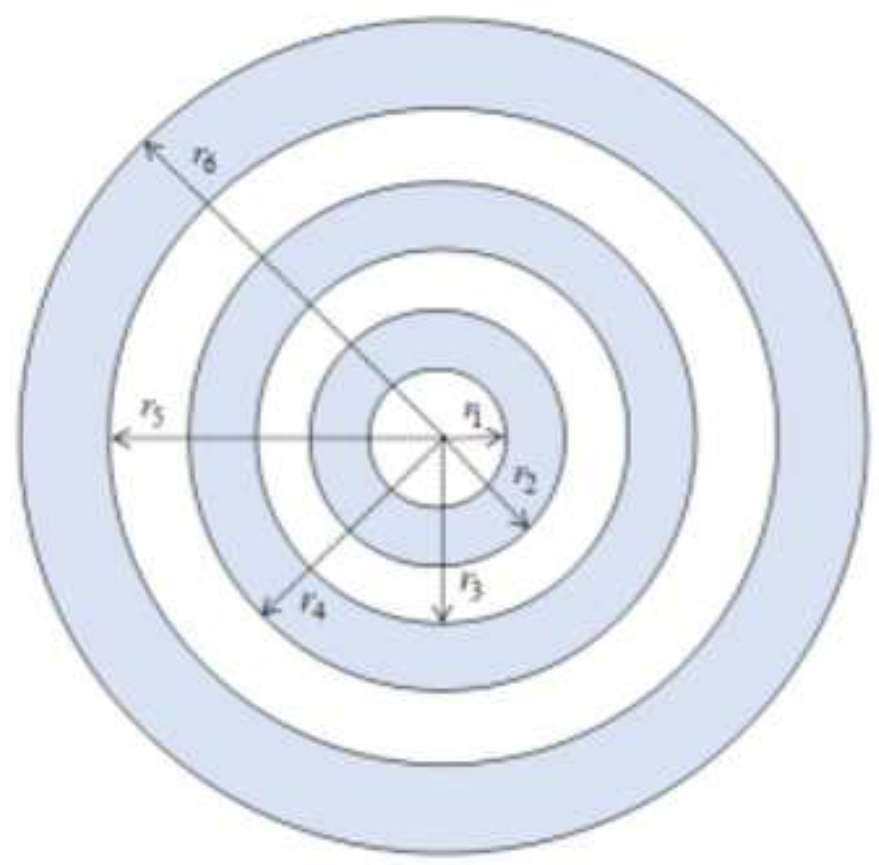

Figure 9 


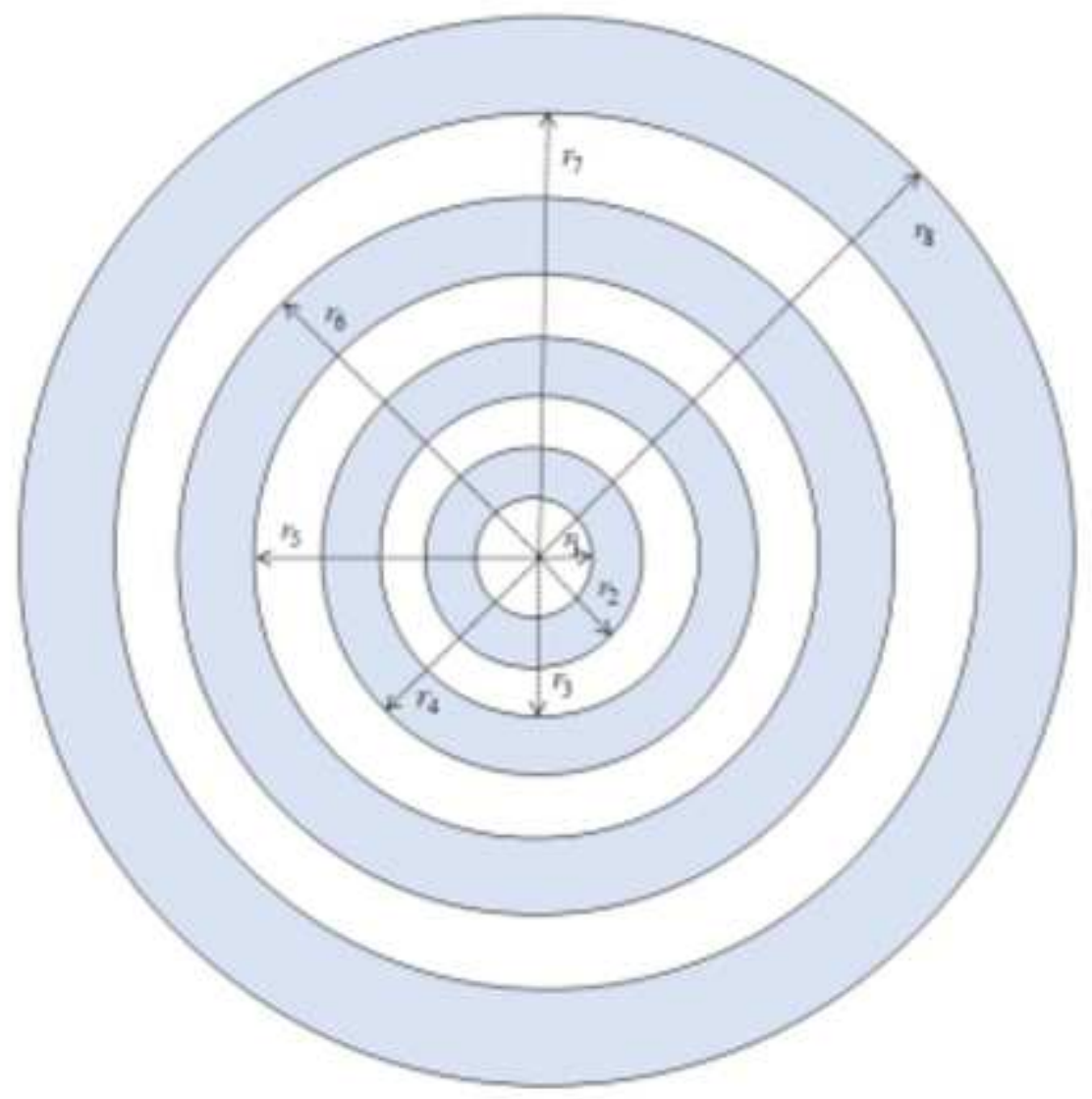

Figure 10

Cross section MWCNT

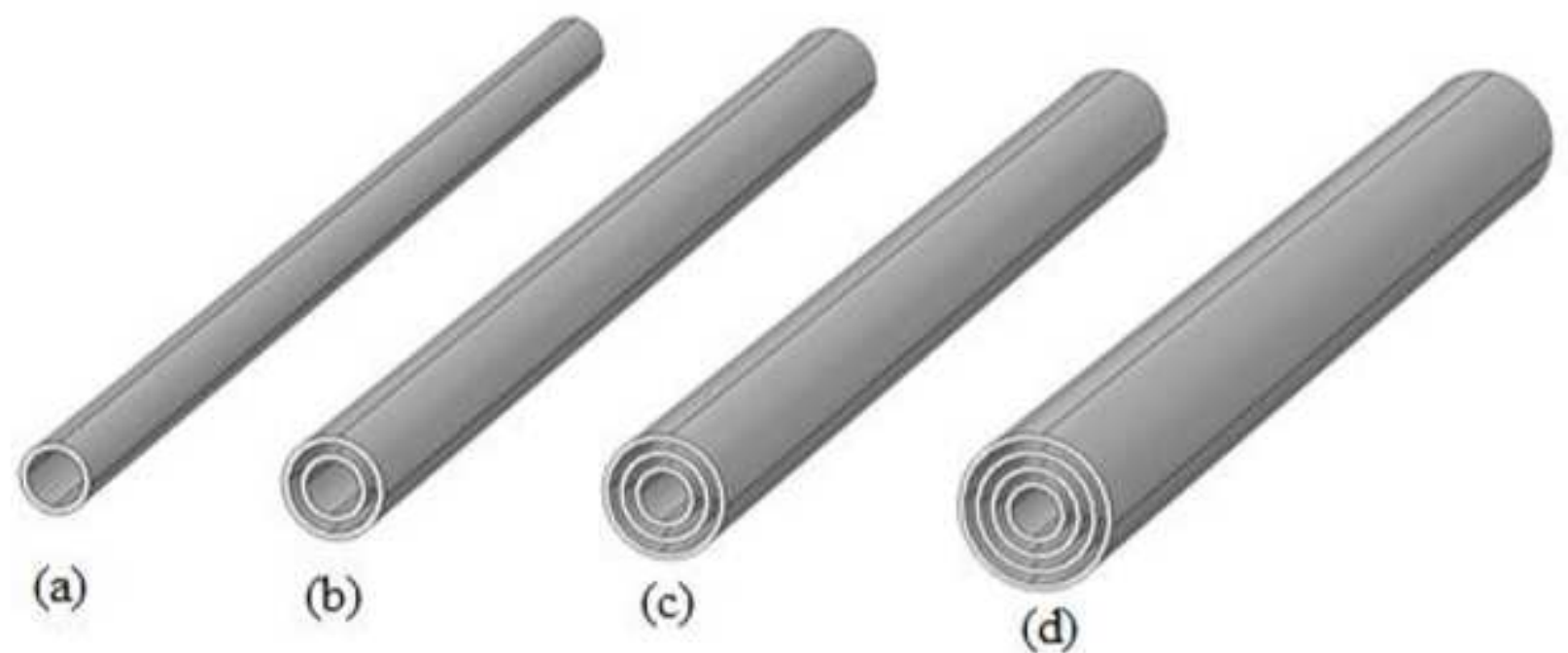

Figure 11

CNT continum shell (a) SWCNT (b) DWCNT (c) TWCNT (d) MWCNT 


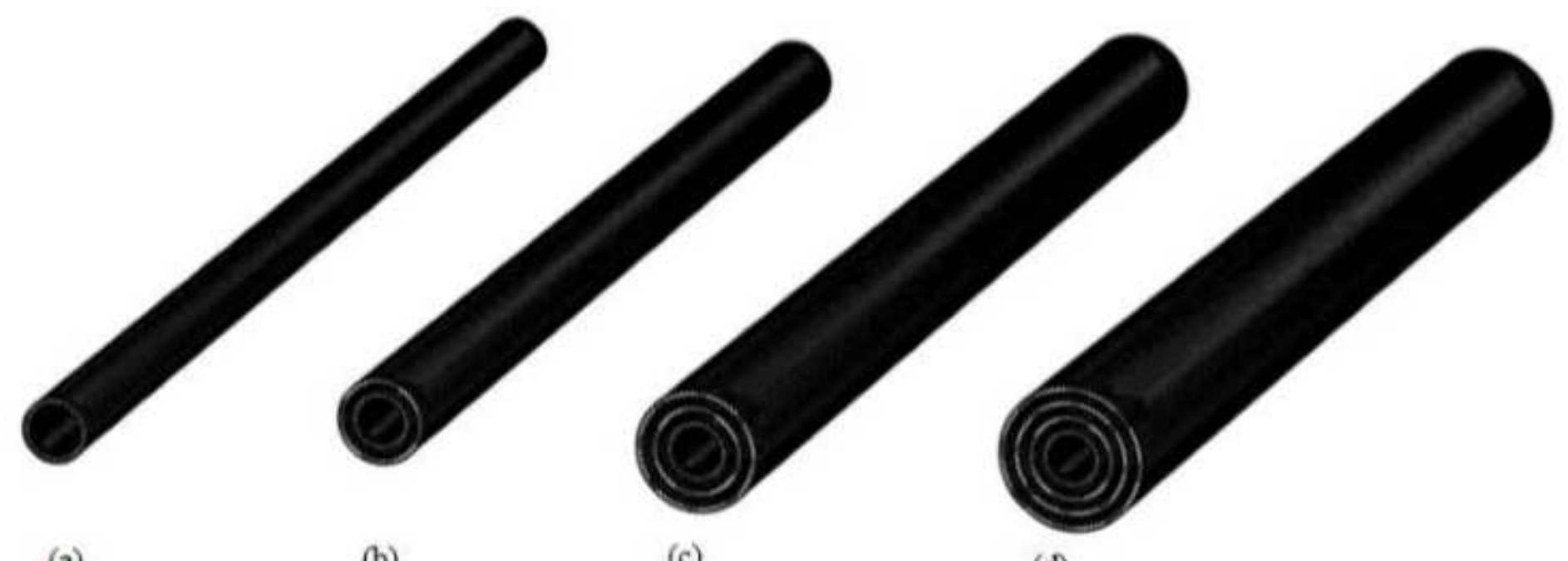
(a)
(b)
(c)
(d)

Figure 12

CNT meshed continum shell (a) SWCNT (b) DWCNT (c) TWCNT (d) MWCNT Temperature $(\mathrm{K})$

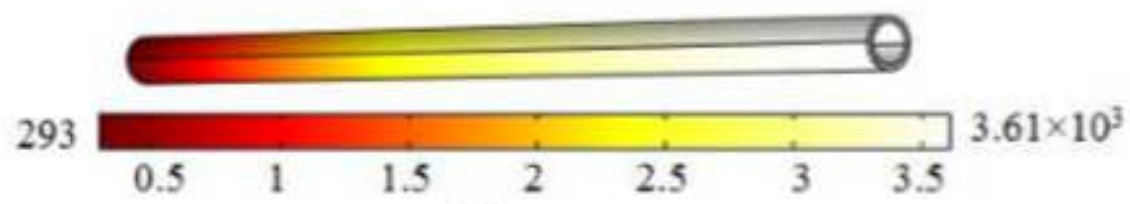

(a)

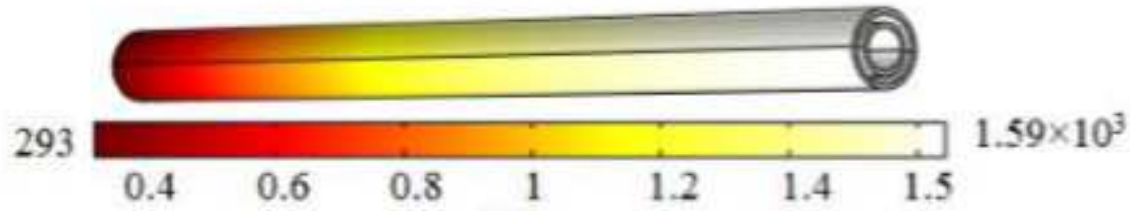

(b)

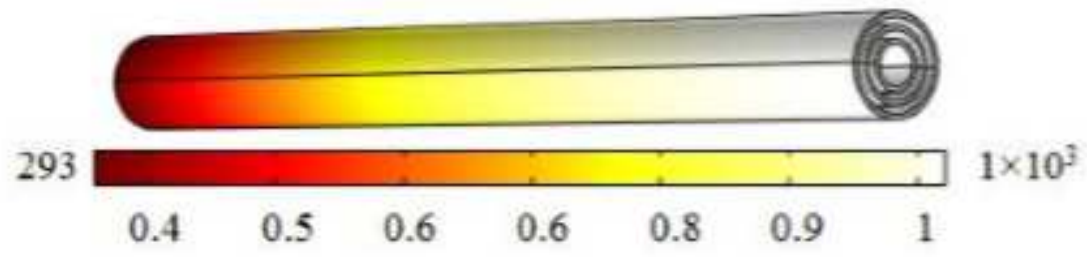

(c)

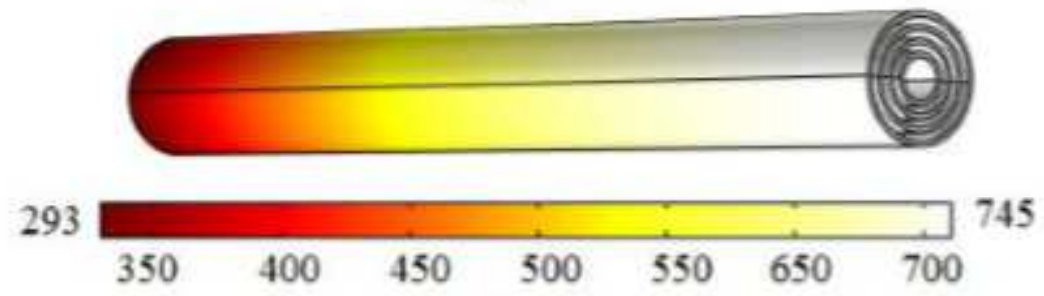

(d) 
Figure 13

Temperature distribution (a) SWCNT (b) DWCNT (c) TWCNT (d) MWCNT

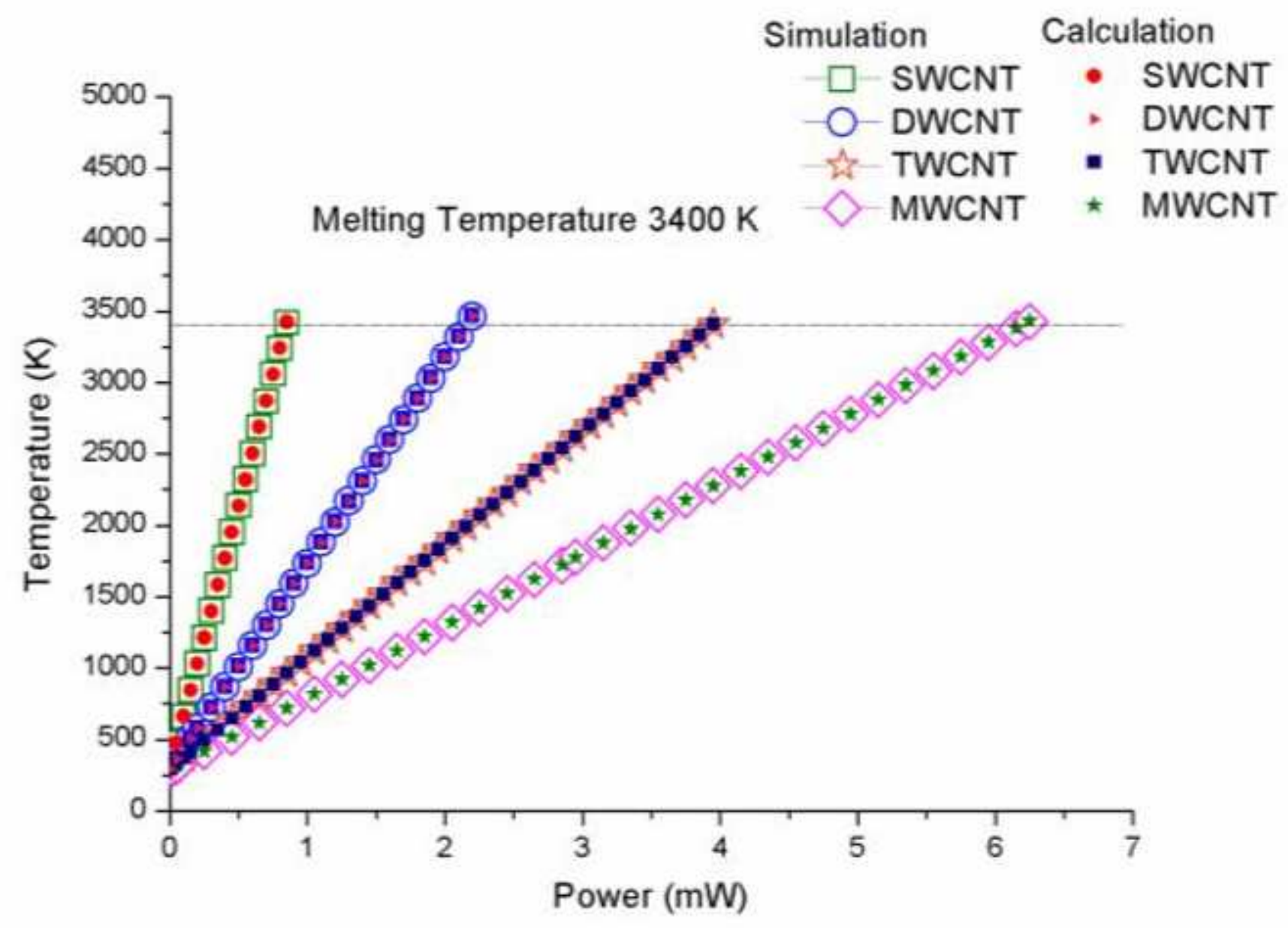

Figure 14

Temperature as a function of power for layered CNTs 


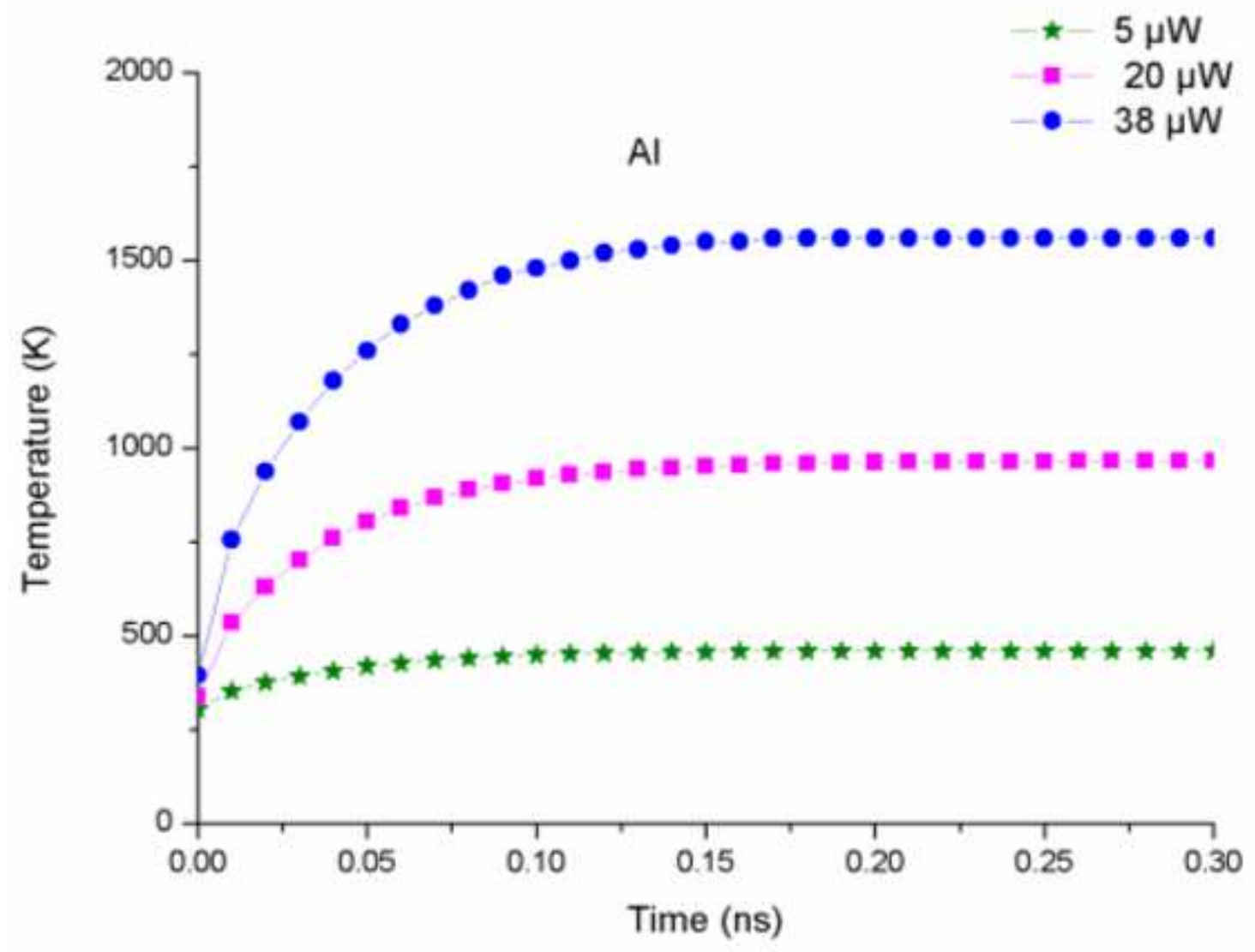

Figure 15

Transient temperature for Al interconnect 


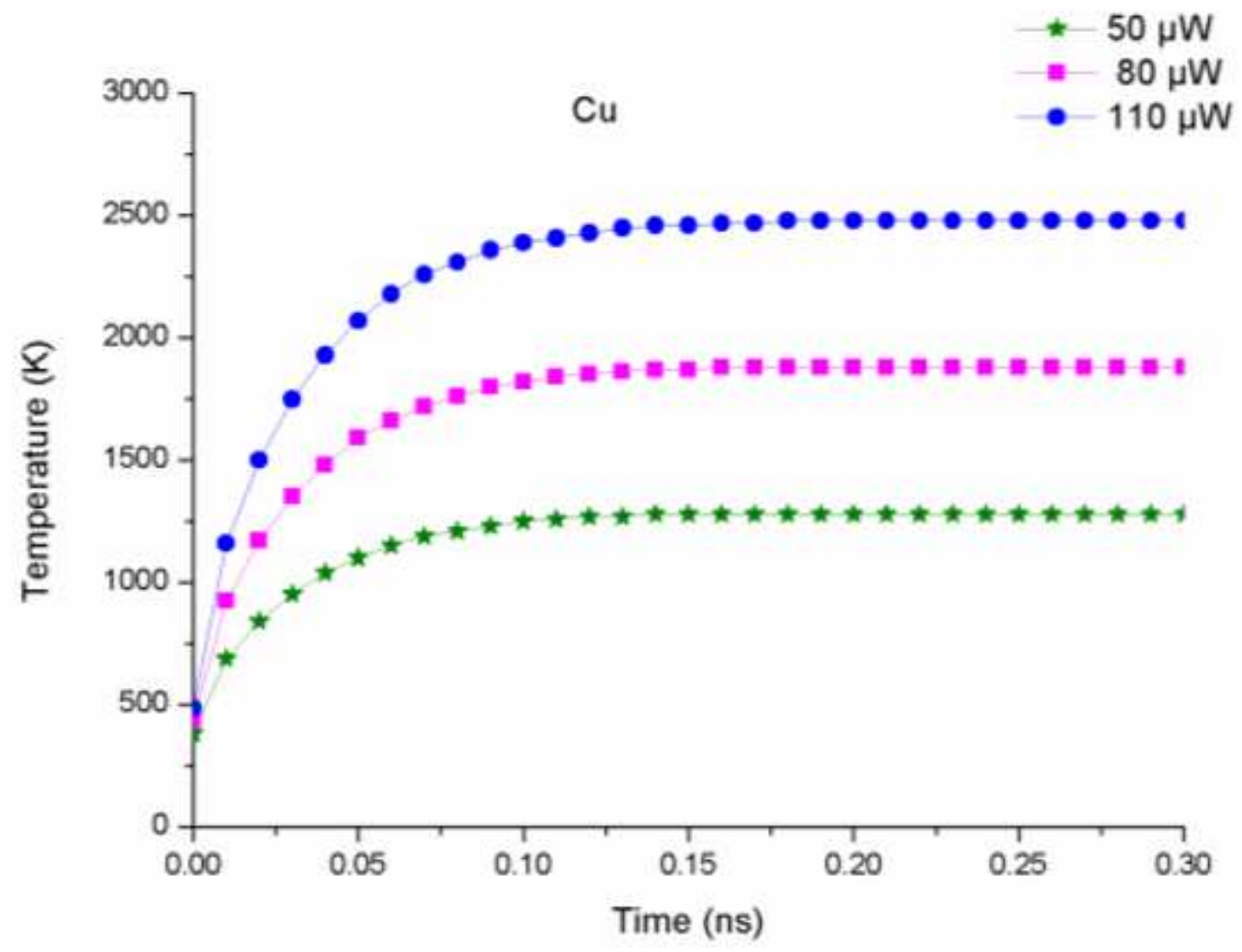

Figure 16

Transient temperature for $\mathrm{Cu}$ interconnect 


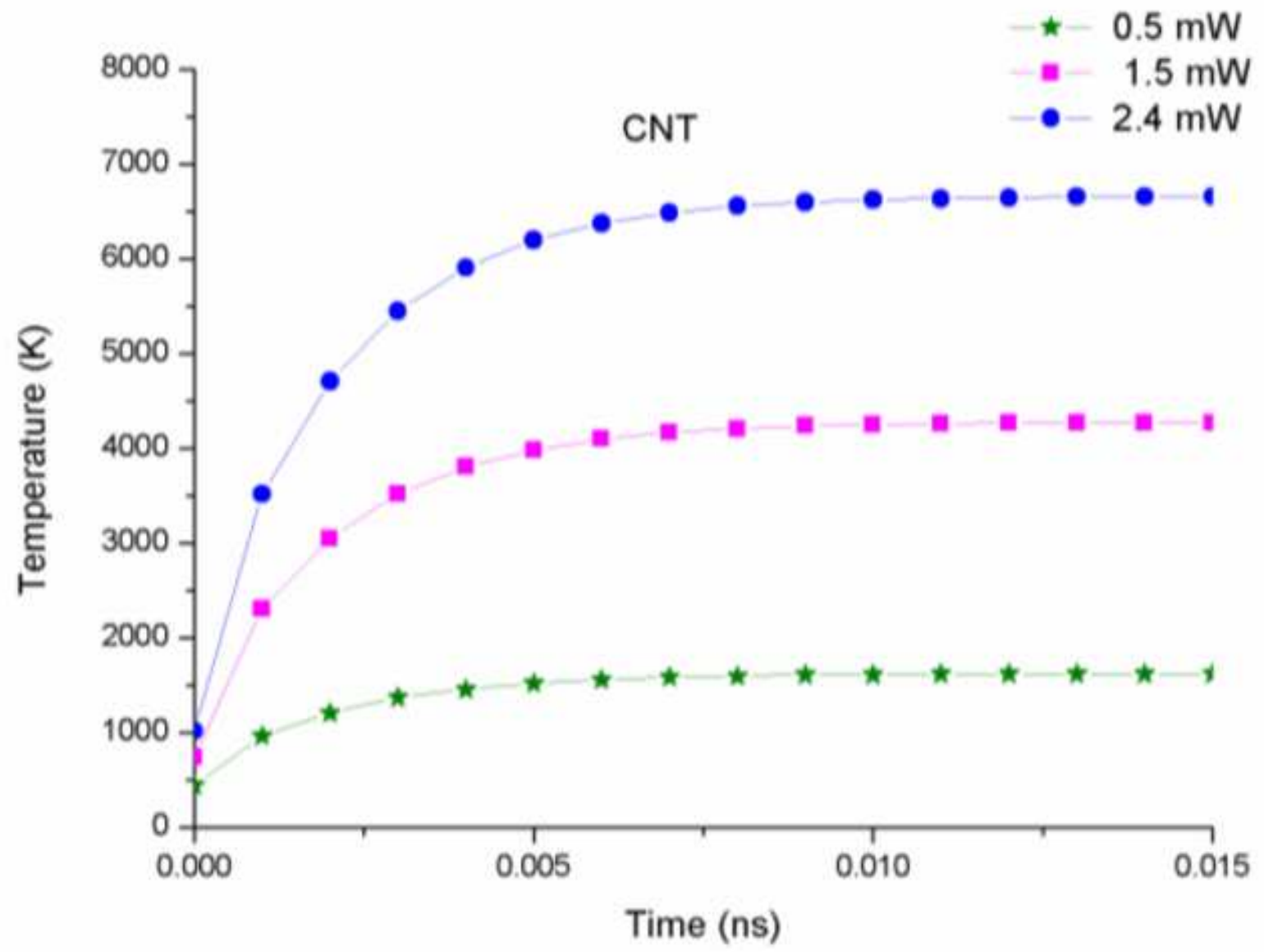

Figure 17

Transient temperature for CNT 


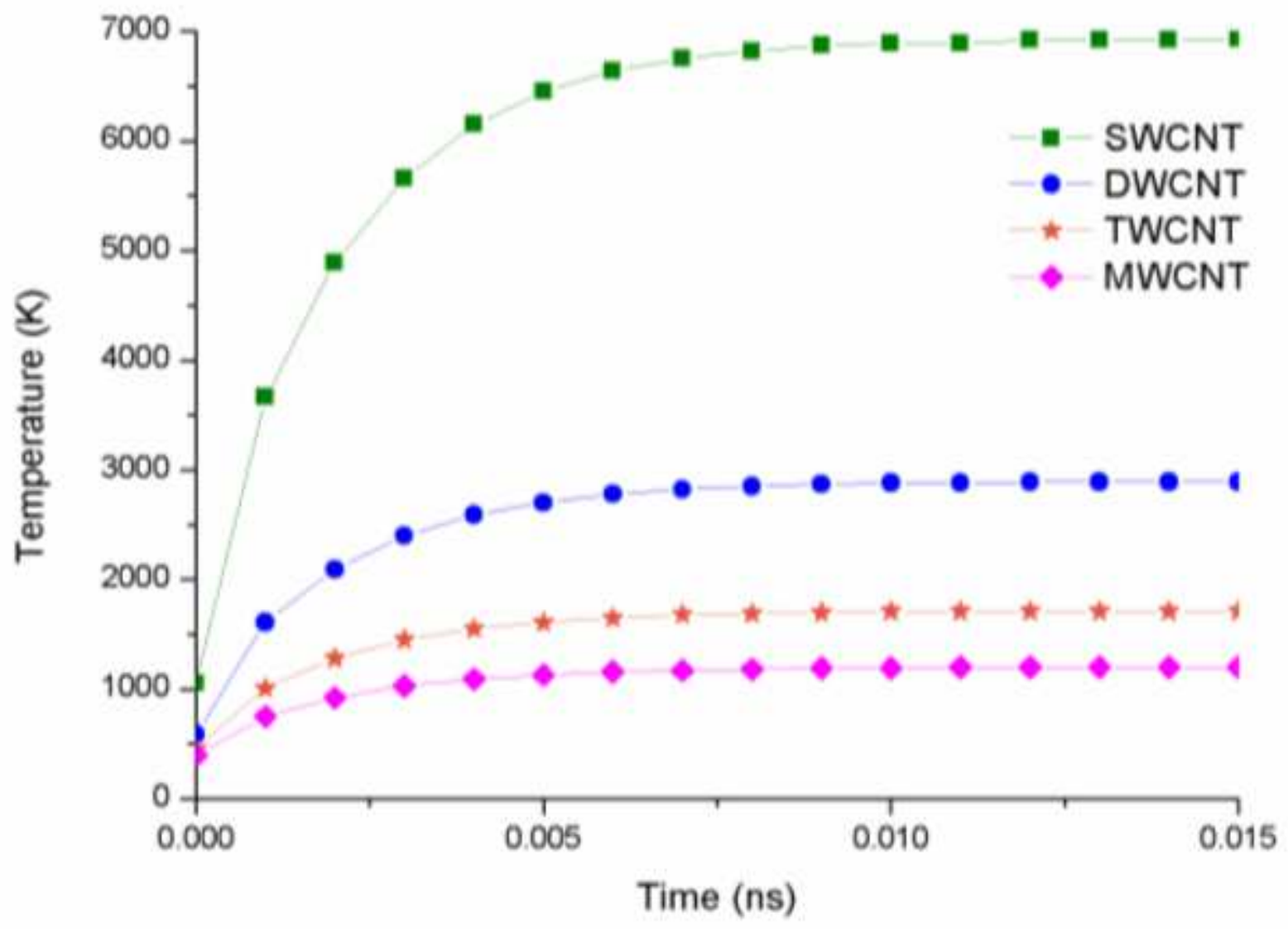

Figure 18

Transient temperature for SWCNT, DWCNT, TWCNT and MWCNT 